University of Nebraska - Lincoln

DigitalCommons@University of Nebraska - Lincoln

4-5-2021

\title{
S Is for Sandhill: A Crane Alphabet
}

Paul A. Johnsgard

Follow this and additional works at: https://digitalcommons.unl.edu/zeabook

Part of the Behavior and Ethology Commons, Environmental Education Commons, Natural Resources Management and Policy Commons, Ornithology Commons, and the Terrestrial and Aquatic Ecology Commons

This Book is brought to you for free and open access by the Zea E-Books at DigitalCommons@University of Nebraska - Lincoln. It has been accepted for inclusion in Zea E-Books by an authorized administrator of DigitalCommons@University of Nebraska - Lincoln. 


\section{(3) Is for Sandhill}

\section{A Crane Alphabet}
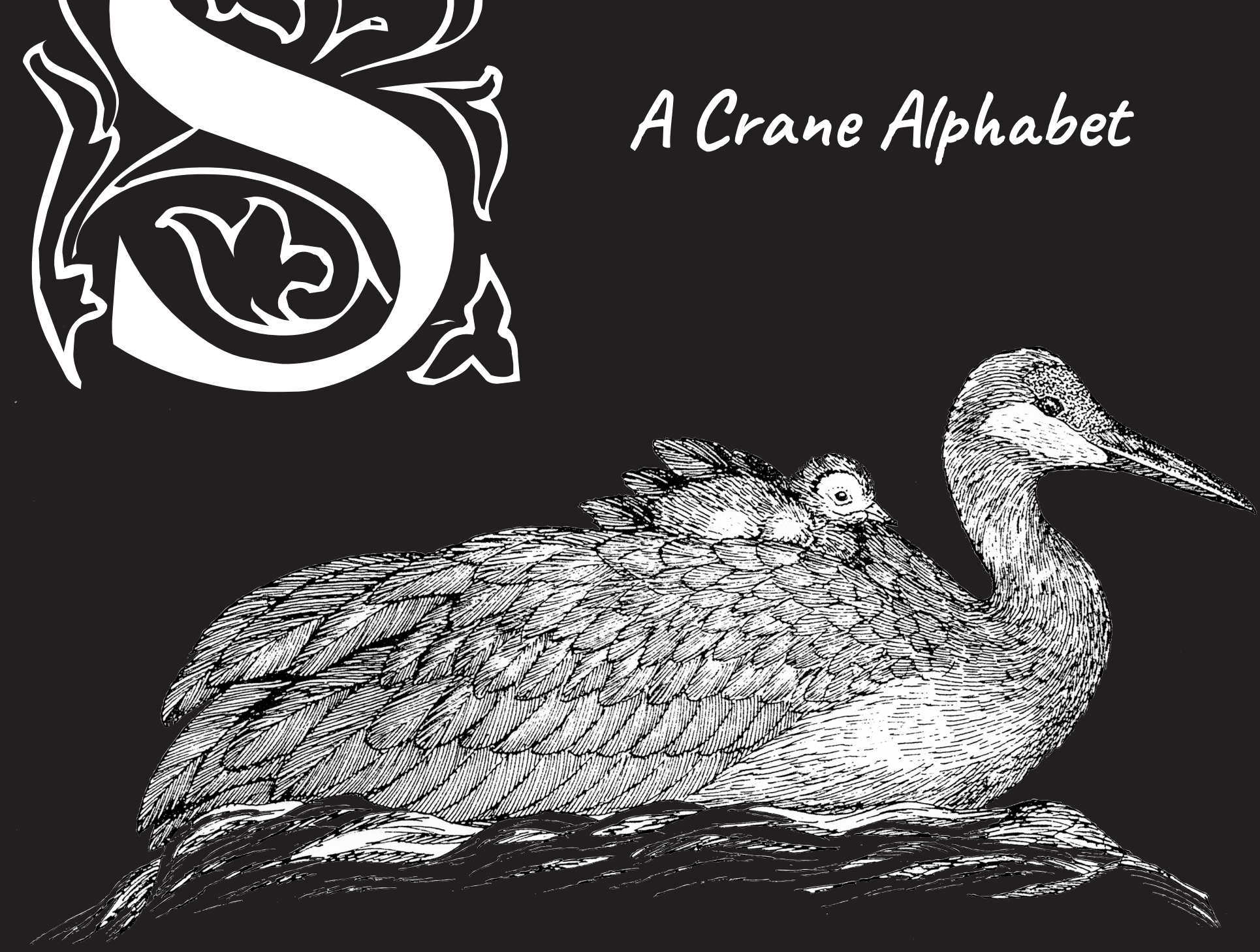

Paul Johnsgard 
This is a book of cranes, from A to Z, written and illustrated by the world's foremost authority on the 15 species of these wonderful and ancient birds. It is a book for all ages, and for all who love and marvel at the beauty, order, and variety of the natural world.

Cranes exhibit complex behavior, pair-bonding, and fascinating social interactions. They migrate huge distances, crossing continents, oceans, and mountains between their nesting and wintering areas. Seven of the world's 15 crane species are listed as "vulnerable," three as "endangered," one as "critically endangered," and only three as of "least concern." Conservation efforts have brought back whooping cranes from the brink of extinction, but the threats to all cranes posed by habitat reduction and climate change are real.

This is an opportunity to share the wonder of these magnificent birds with young and old, and to appreciate their gift to us all.

Paul Johnsgard is emeritus professor in the School of Biological Sciences at the University of Nebraska-Lincoln. He is the author of roughly 100 books of ornithology and natural history and is a recognized champion of conservation and environmental preservation.

\section{Zea Books}

Lincoln, Nebraska

ISBN 978-1-60962-196-4 (e-book)

doi: 10.32873/unl.dc.zea.1278

\section{Nebraskiana \\ Lincoln}




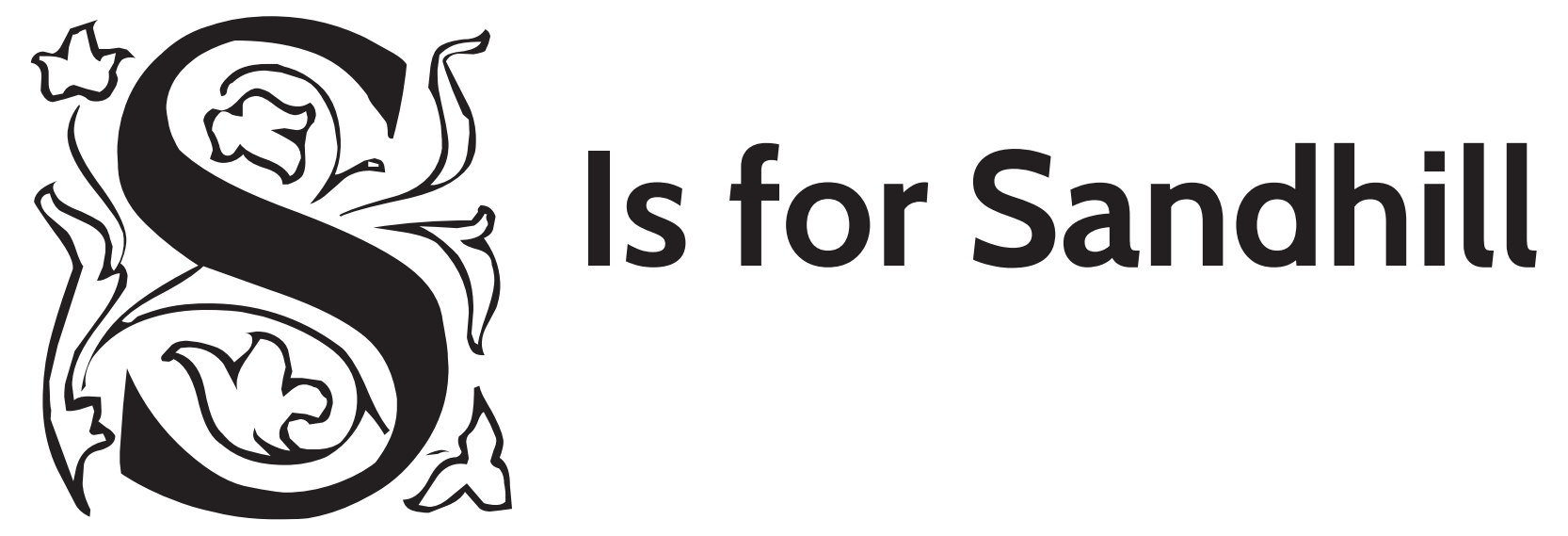

\section{A Crane Alphabet}

Paul A. Johnsgard

School of Biological Sciences

University of Nebraska-Lincoln

Zea Books

Lincoln, Nebraska

2021

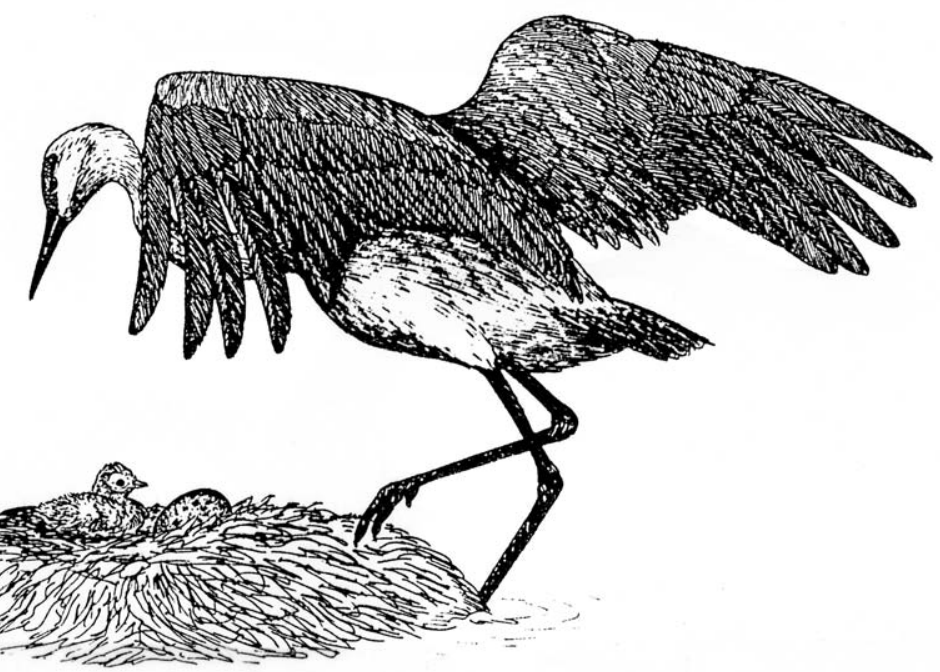


Copyright $\odot 2021$ Paul A. Johnsgard

ISBN: 978-1-60962-195-7 paperback

ISBN: 978-1-60962-196-4 e-book

doi: 10.32873/unl.dc.zea.1278

Composed in Cabin and Caveat types, with Preciosa and Zallman initials.

Zea Books are published by the University of Nebraska-Lincoln Libraries

Electronic (pdf) edition available online at https://digitalcommons.unl.edu/zeabook/

Print edition available from Lulu.com at https://www.lulu.com/spotlight/unllib

UNL does not discriminate based upon any protected status.

Please go to https://www.unl.edu/equity/notice-nondiscrimination

Nebraskia

Lincoln
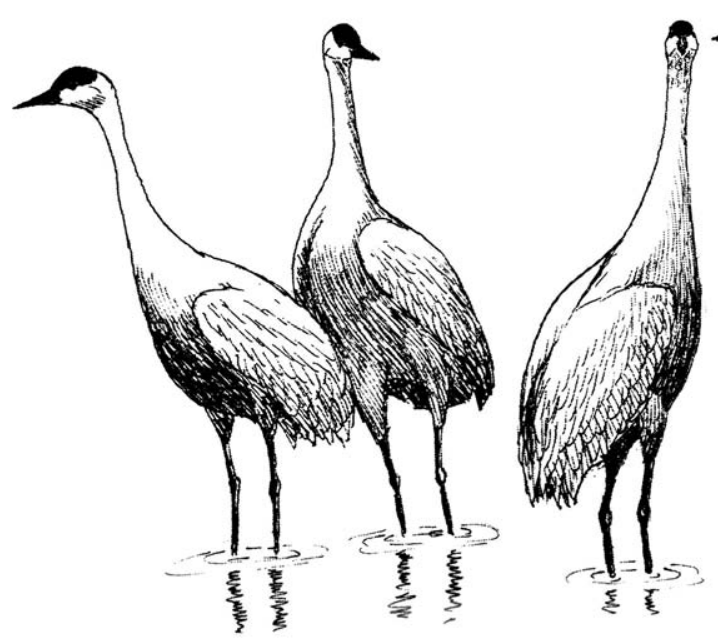

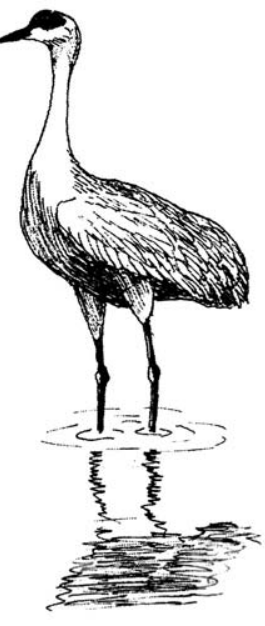




\section{Acknowledgments}

Above all, I must declare gratitude to the cranes, who have made my life rich, exciting, and wonderful and have exposed me to an additional dimension of reality and perception that I could not have imagined possible for a human to experience.

Additionally, I bow in reverence to Paul Royster and Linnea Fredrickson, who have been able to turn my words and drawings into magic on mere paper and have in a literal sense bestowed on me a kind of limited immortality beyond my earthly years.

Paul A. Johnsgard

March 21, 2021

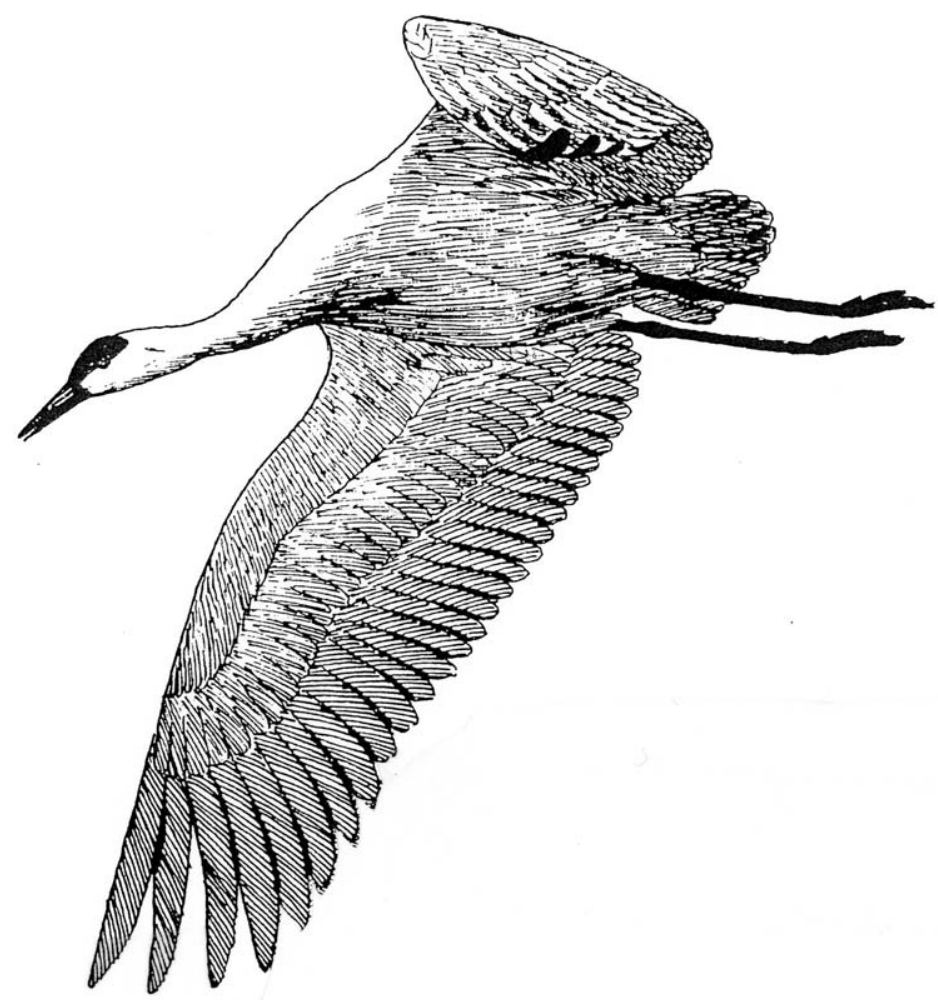


is for alpha, meaning first, or the best.

If you are talking of birds, IIl choose cranes over the rest.

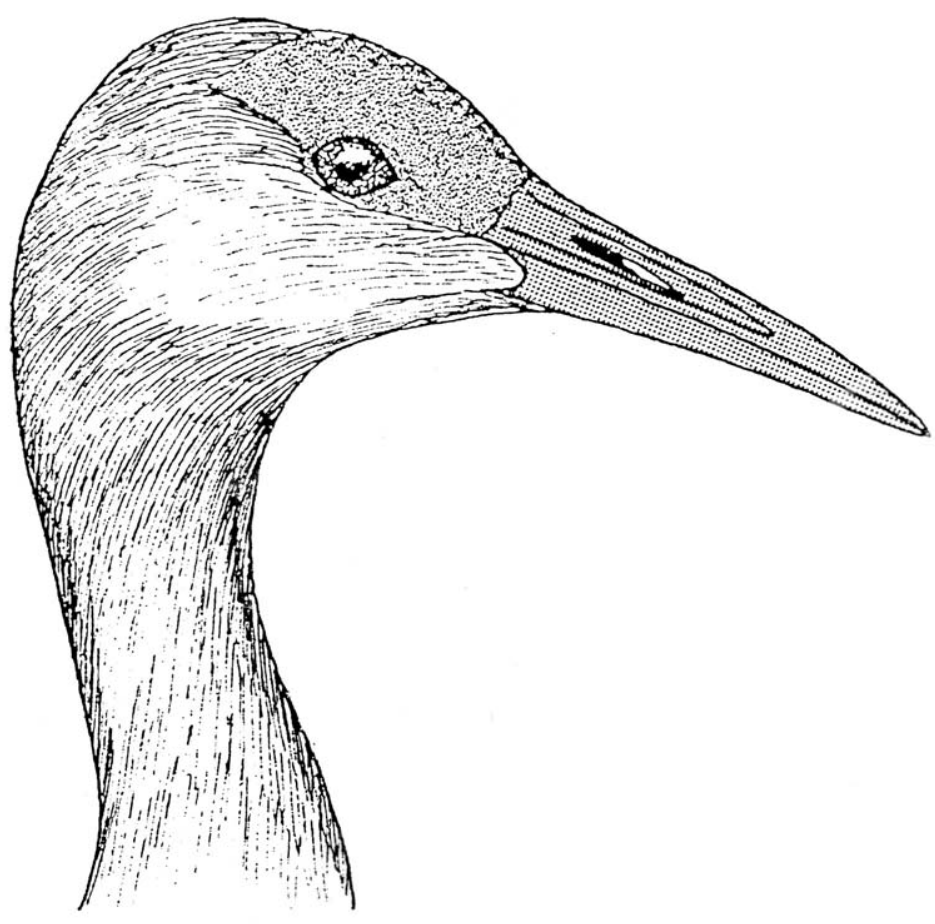

An adult sandhill crane (left) and whooping crane (right) 
Cranes are a closely related group of 15 species of long-legged and longnecked wading birds that occur on all the world's continents except South America and Antarctica. They range in height from about 3 to 6 feet, and adults of the largest species might weigh in excess of 18 pounds. The largest number of crane species (eight) live in Asia, where they are universally beloved and widely regarded as symbols of longevity, fidelity, and happiness.

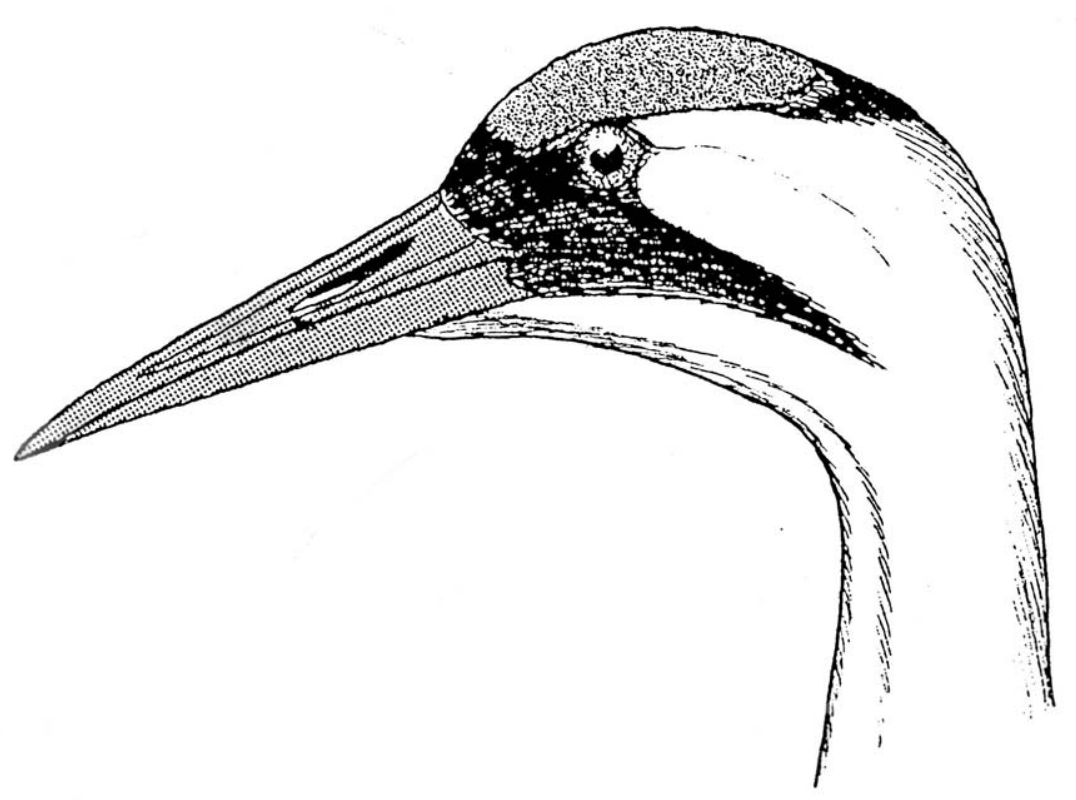




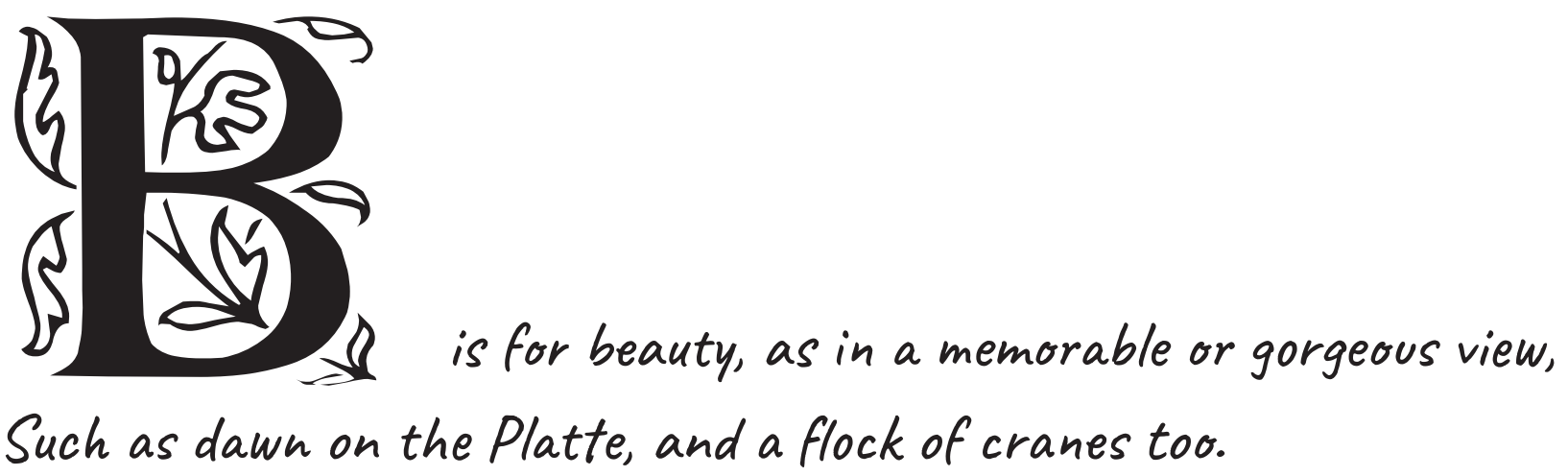

Although cranes are not brightly plumaged, adults of most species exhibit bare forehead skin, which can vary from pink to bright red, with the color intensity reflecting a bird's varied internal states of fear, aggression, or relaxation. Bright red facial skin patches or throat wattles also occur in several species. These features and the birds' diverse plumage patterns add to the beauty and attractiveness of cranes. 


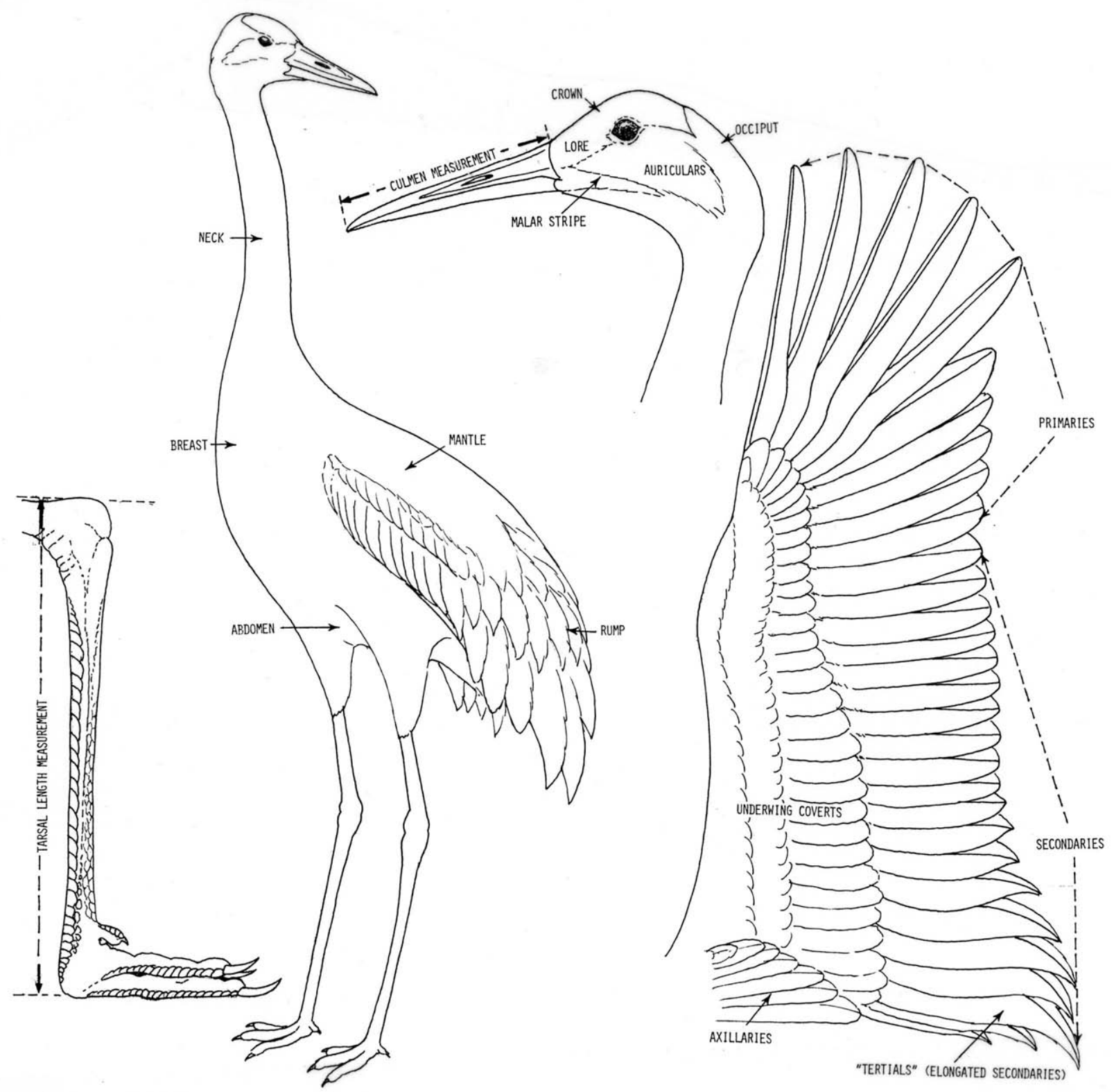

External anatomy of a crane 


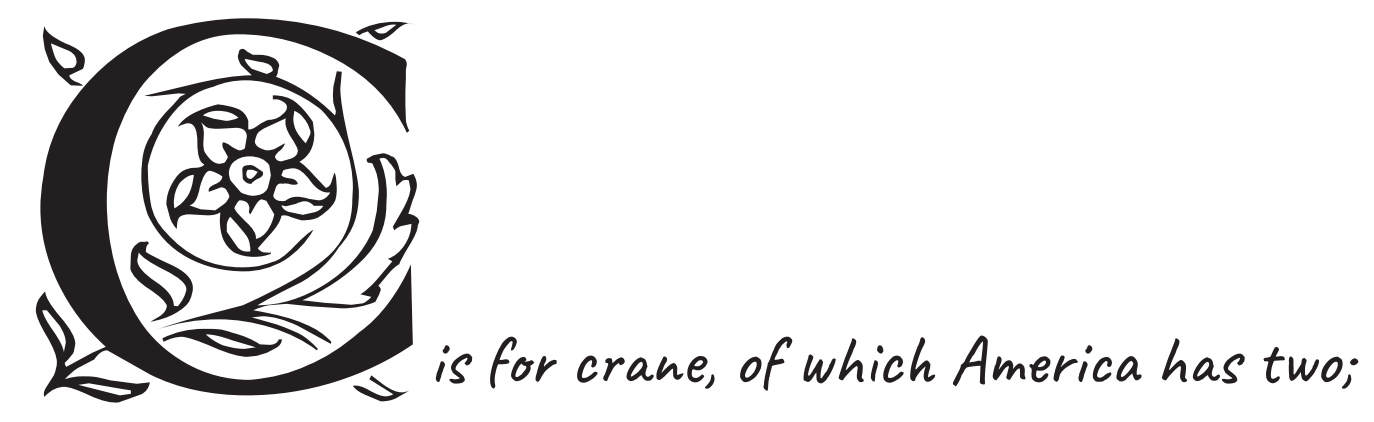

The sandhill is abundant, the whooping numbers only a few.

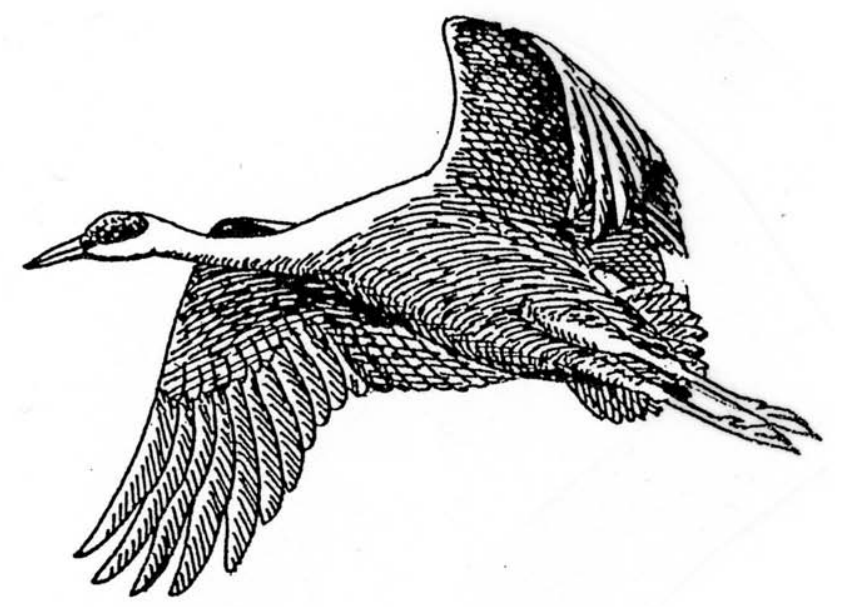

Three sandhill cranes in flight 
America's two species of cranes could hardly be more different. The abundant sandhill crane breeds across most of central and northern North America, and individuals of the geographically scattered populations range in weight from about 5 to 12 pounds. Adult whooping cranes weigh 15 to 17 pounds and are among the heaviest (and rarest) of the world's cranes.

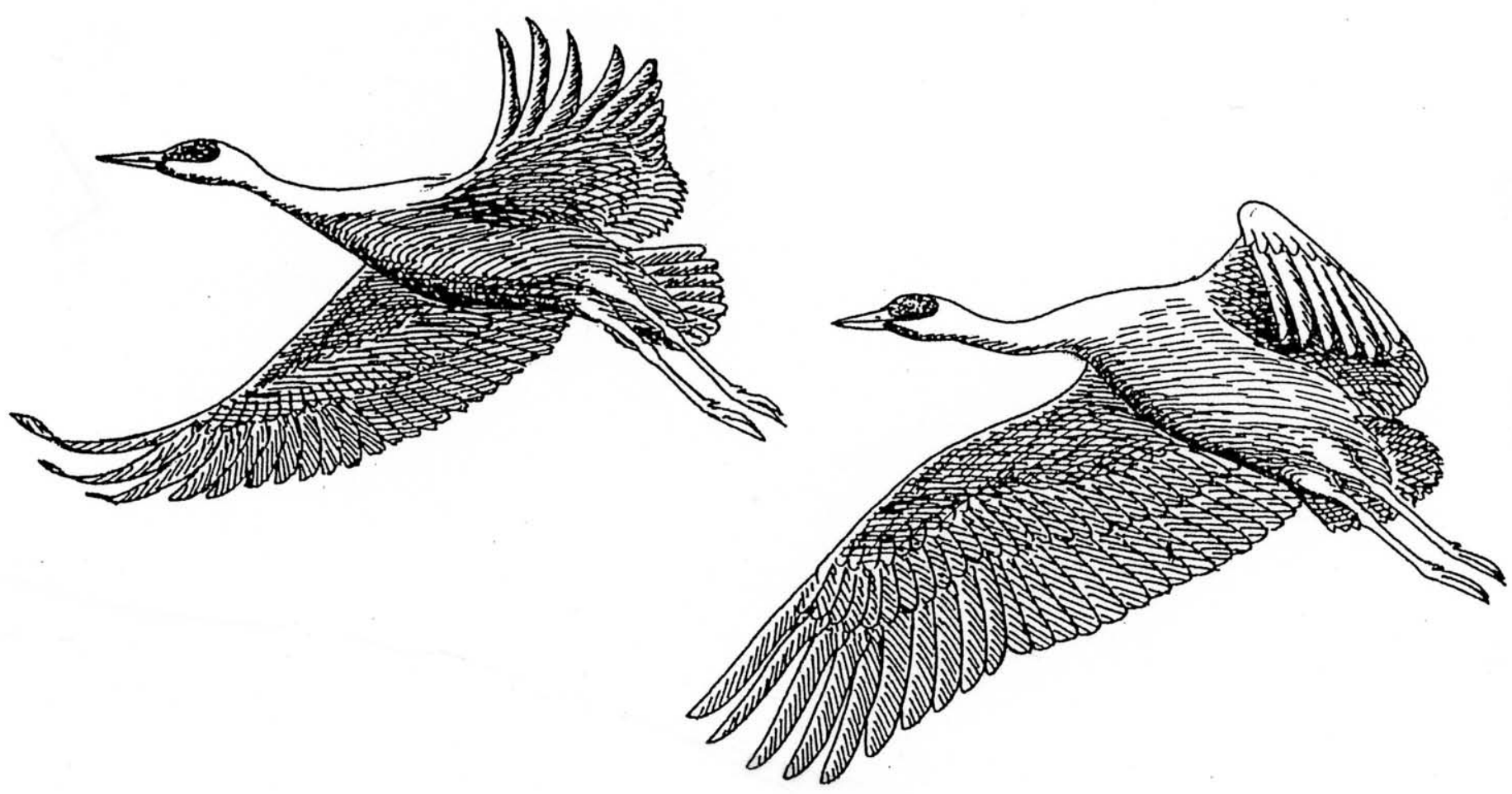




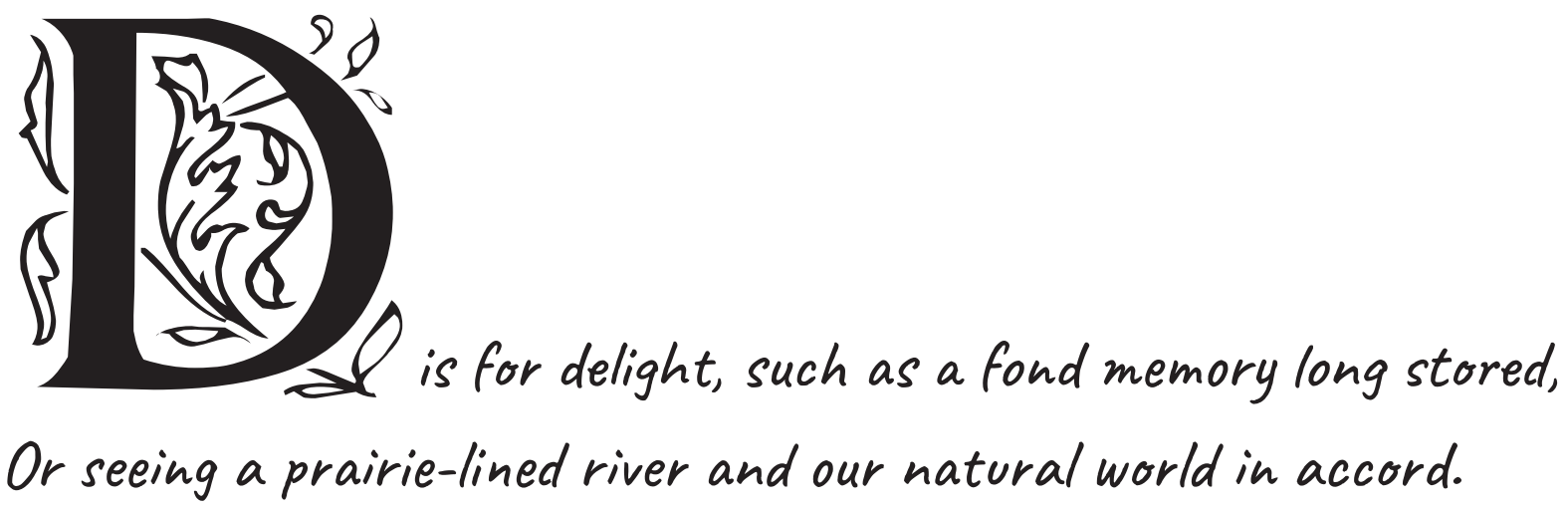

All sandhill cranes are uniformly but delightfully gray-plumaged as adults, except for whitish chins and dark blackish outer wing feathers. However, breeding sandhills "paint" their body feathers with rusty brownish to grayish pigments of rotting marsh vegetation, probably to help conceal themselves among dead vegetation during nesting. Adult whooping cranes have entirely white plumages, except for ten pairs of black outer wing feathers ("primaries"). All cranes replace all their body feathers during an annual molt following breeding, and many species then become flightless for a month or more while their major wing feathers are being replaced. 


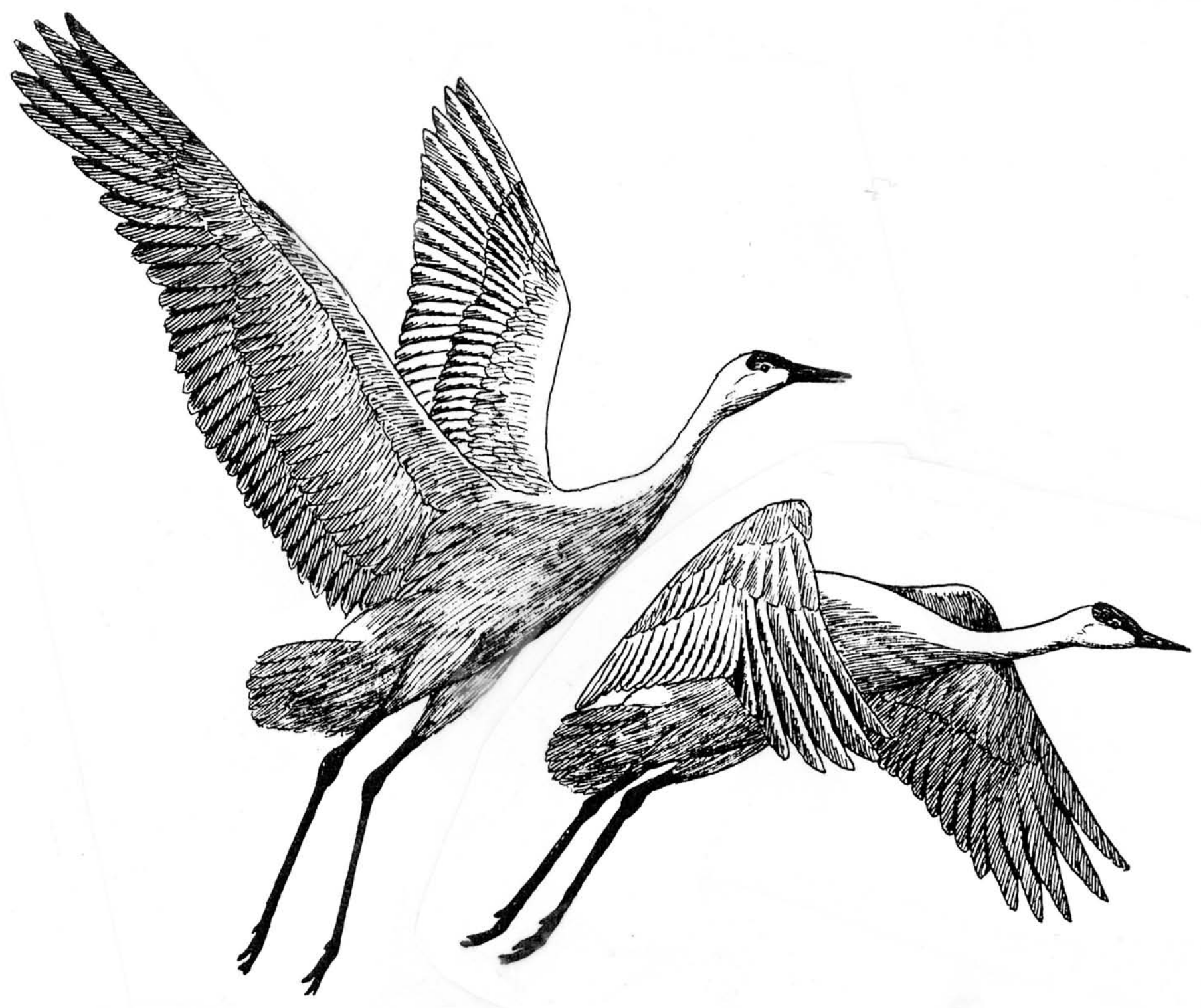

Two sandhill cranes in flight 


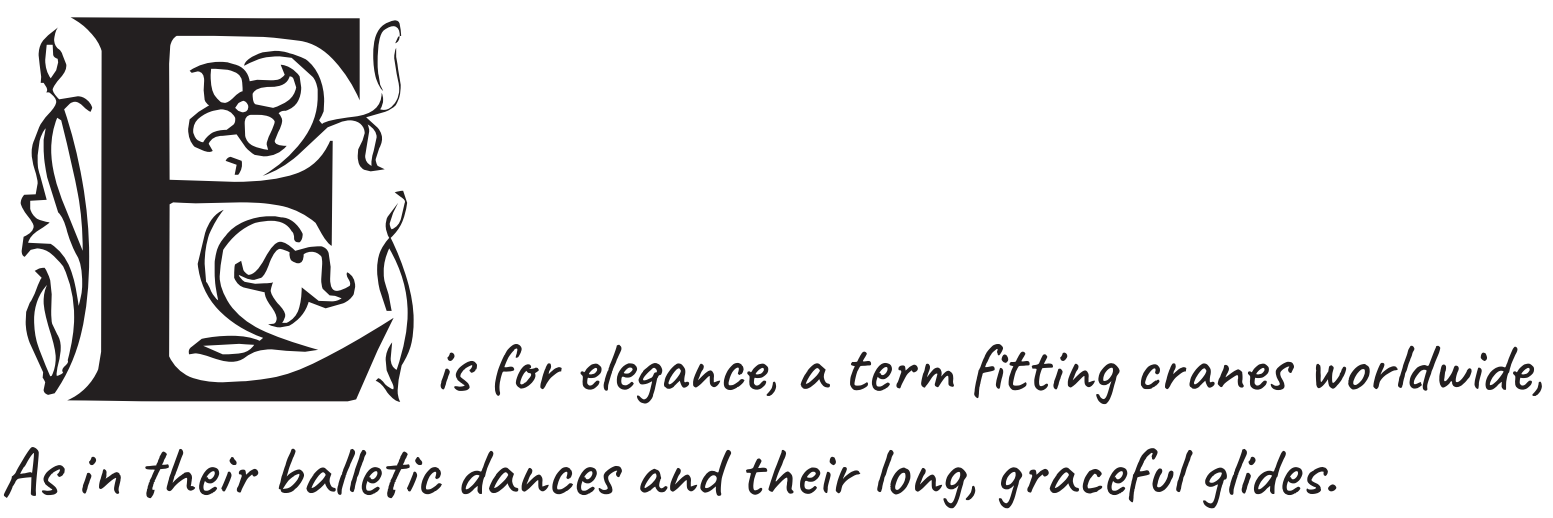

Cranes are unique birds in that all 15 species "dance" as important parts of their social behavior, but the dances are so complex and variable among species that their meanings and possible functions are still subjects of research and speculation. Certainly, pair-bonding must be one of their functions, but pairing and pair maintenance among cranes is mostly achieved by loud and synchronous "unison calling" by the members of a pair or a potential pair. It is often triumphantly performed after an aggressive interaction between two pairs, and if other family members are present, they often join in the chorusing. 


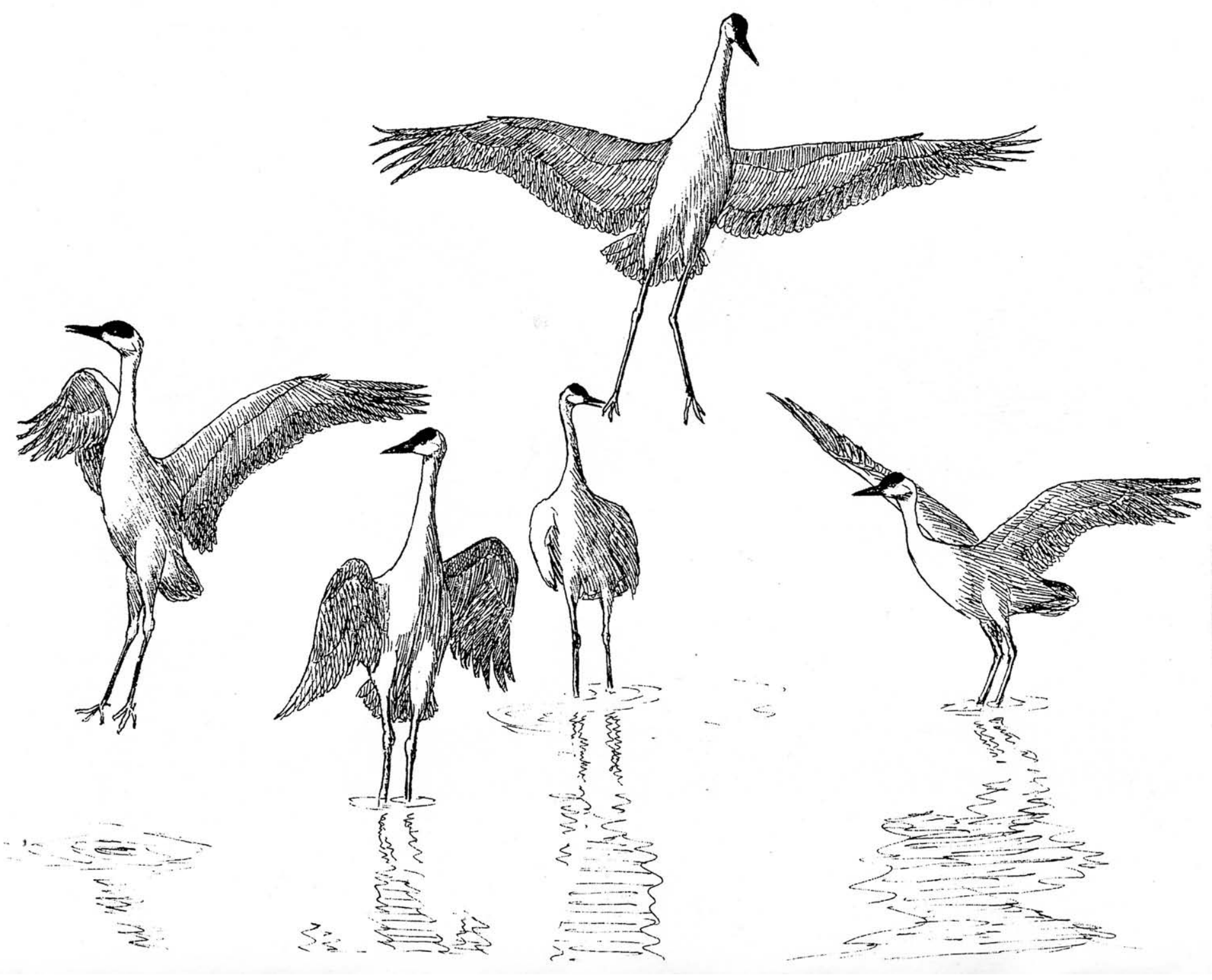

Sandhill cranes dancing in shallow water 


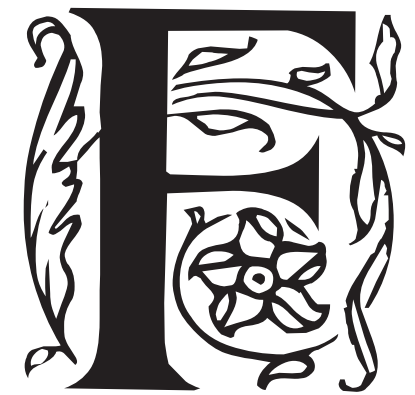

is for family, the heart of all crane social life.

Their strong family bonds weather both good times and strife.

Cranes of all species are notable for their strong pair and family bonds. They typically become sexually mature at two to three years of age, but there are probably some species differences. Florida sandhill crane males may attempt to breed at two years and females at three, but their first successful breeding averages three years among males and nearly five years in females. In a Florida study, during which 74 pair-bonds were broken over a study period of 426 pairyears (or about one pair split per six pair-years), 68 percent of the breaks were because of the death of a mate and 32 percent because of "divorce." The most common cause of divorce was a failure of the pair to reproduce successfully. 


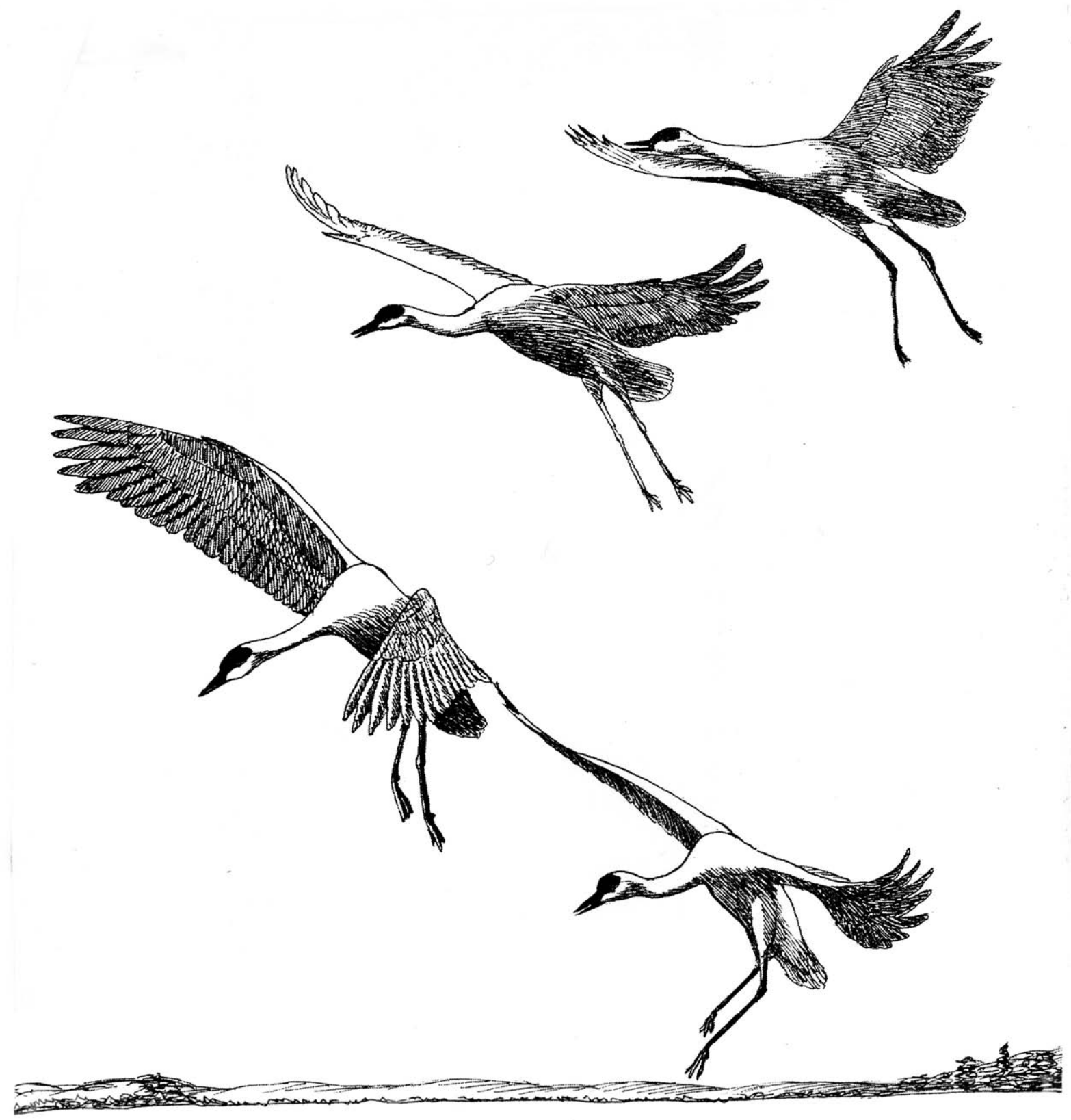

Sandhill cranes landing on the Platte River 


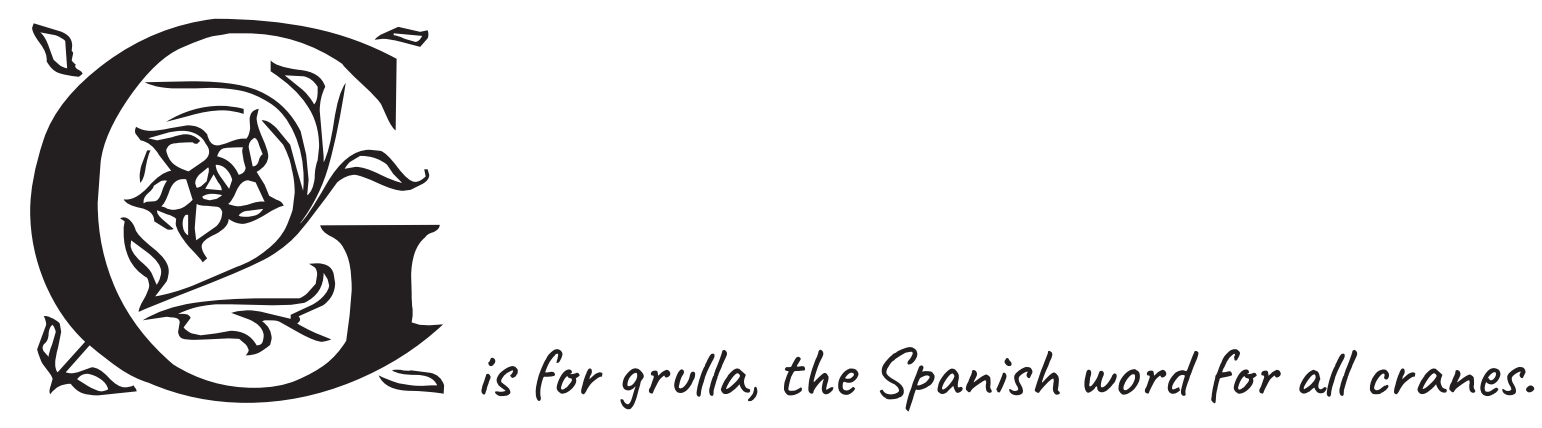

In Mexico, many overwinter on the Chihuahuan plains.

Sandhill cranes range south only to northern Mexico, and whooping cranes have only very rarely been reported there. As is true in the southwestern United States, the cranes roost nightly during winter in variably alkaline wetlands on low flatlands, or playas. From there they fly out daily in search of food, such as emerging green vegetation and, where it is available, waste grains such as corn. 


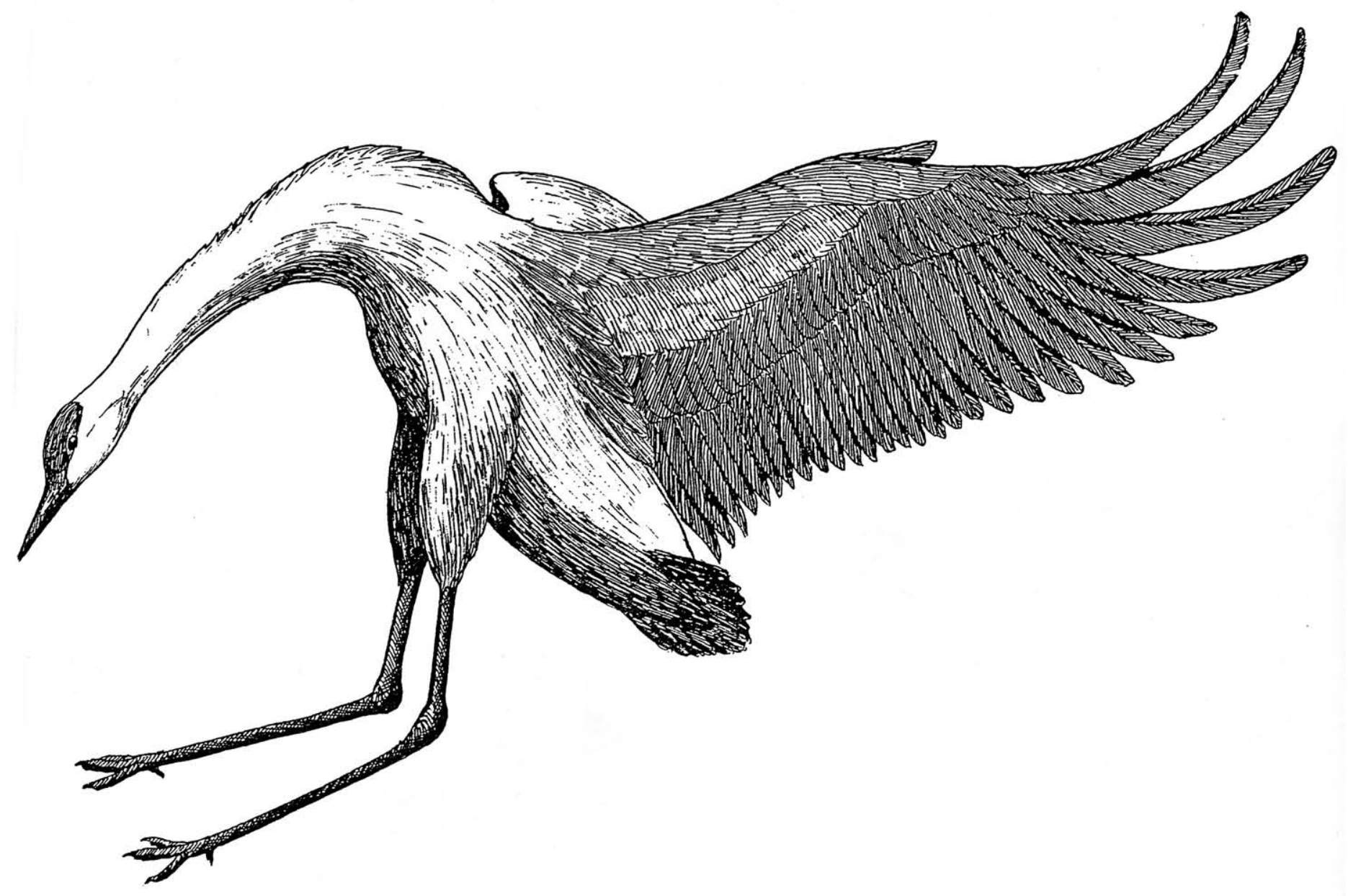

A sandhill crane landing 


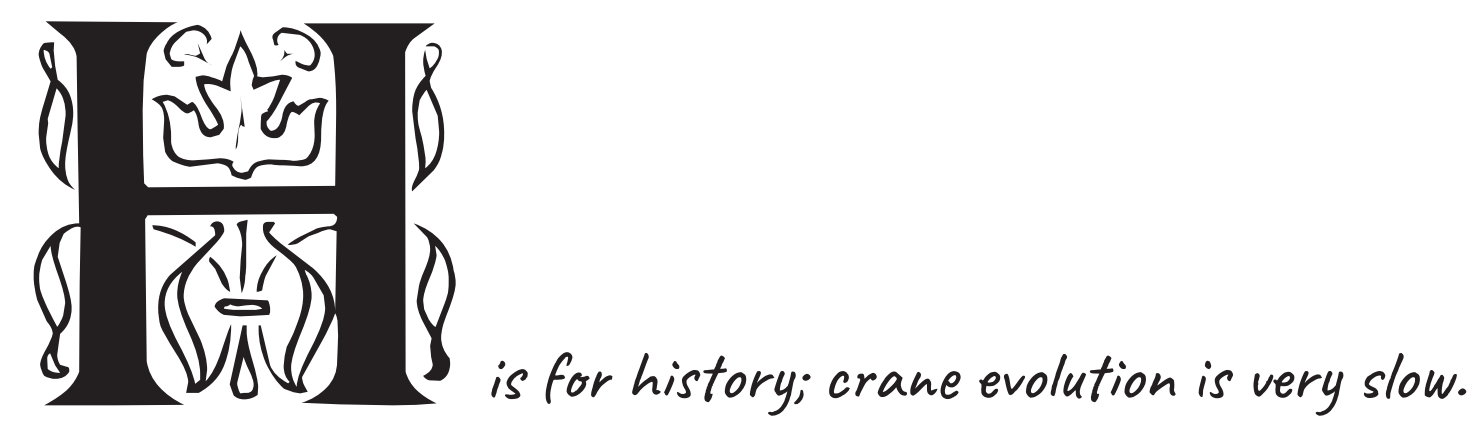

It spans nearly 50 million years, give or take 10 million or so.

Only a few intact bird fossils of any kind are from further back in time than about 40 million years; birds' hollow bones are easily crushed by accumulating deposits of sand, mud, or other sedimentary materials. However, several fossil species of the more advanced groups of cranes (including sandhill and whooping cranes) extend back to the Miocene epoch ( 5 million to 24 million years ago), and some fossils belonging to the more primitive crowned crane group have been found from the Eocene epoch ( 35 million to 60 million years ago). By this time, larger primitive land mammals had replaced nearly all reptiles as the dominant animals on Earth, and birds were just beginning to become important ecological elements. 

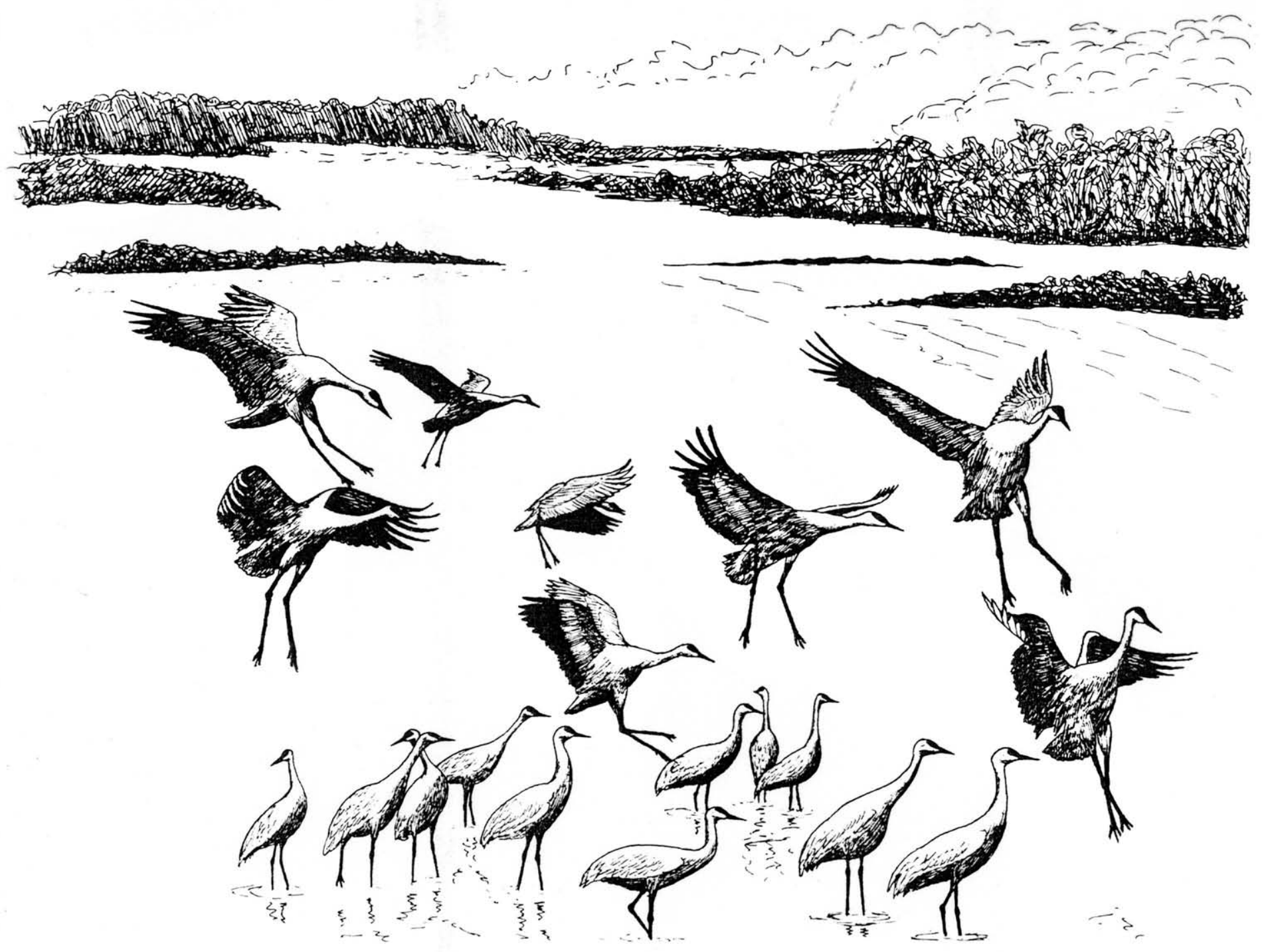

Sandhill cranes gathering on a Platte River roost 


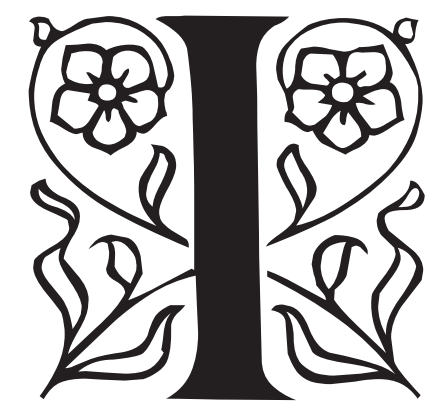

is for incubation, the adult male or female sitting on eggs.

Crouching for 31 days with few breaks must be hard on the legs!

Incubation in cranes is much like that of other birds. It varies in length from 28 to 34 days in various species and under varying conditions. Nearly all cranes lay only two eggs, about two days apart. Whooping cranes share incubation almost equally between the sexes. In one study, one pair exchanged duties about eight times a day, while in two others one of the sexes did most of the nighttime incubation. Because incubation begins with the laying of the first egg, that egg is the first to hatch, often two days before the second. By then the firsthatched chick is out moving about on its own, under the watchful eye of the nonincubating parent. 


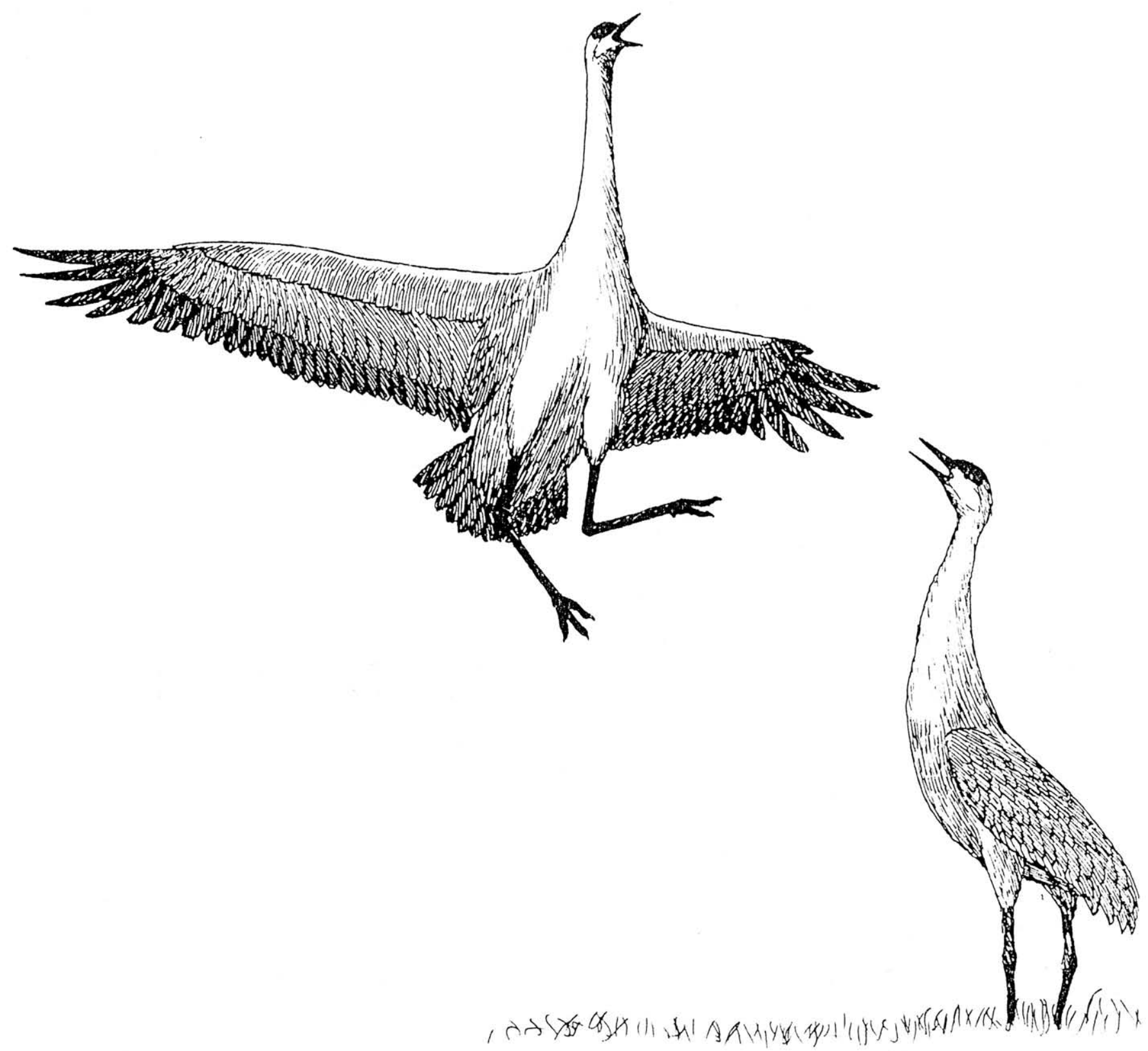

A sandhill crane display-jumping before its mate 


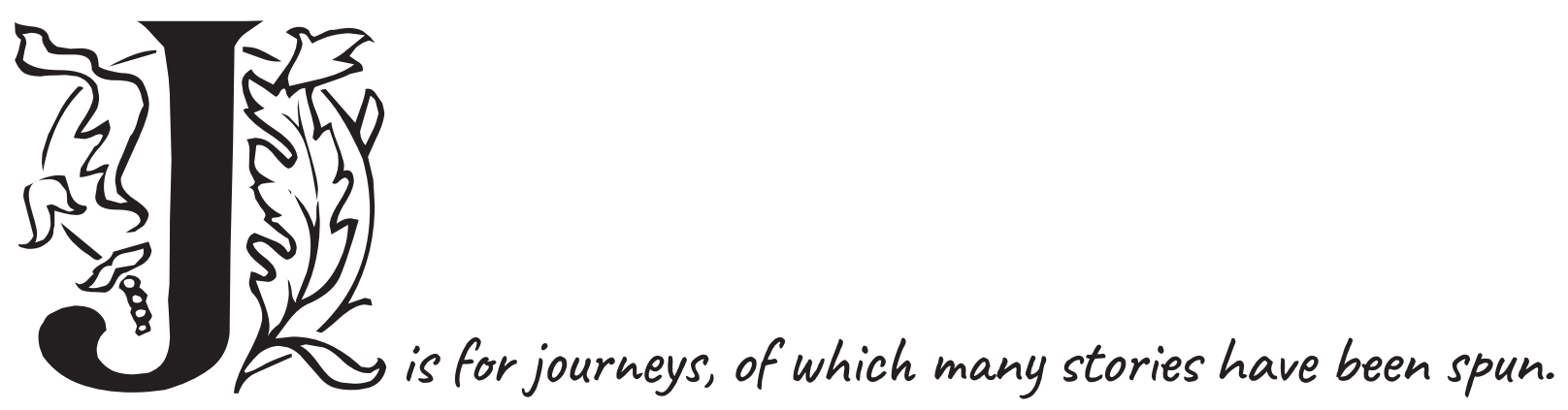

Crane migrations are learned, to be taught each year to their young.

Some crane migrations are epic. Once in early June, I watched sandhill cranes crossing the Bering Strait high above the Pribilof Islands, where the distance from the Alaskan coast to the Siberian coast would be at least 500 miles. Farther south, sandhill cranes cross the Colorado Rocky Mountains over passes probably at least 10,000 feet high. In Asia, the Himalayas are annually surmounted by several crane species; the Eurasian crane has been seen flying over mountain passes there at an elevation of 35,000 feet! The cranes' efficient breathing mechanism, with its several large air sacs that push oxygen through an openlung structure with every breath, makes such amazing flights possible. 


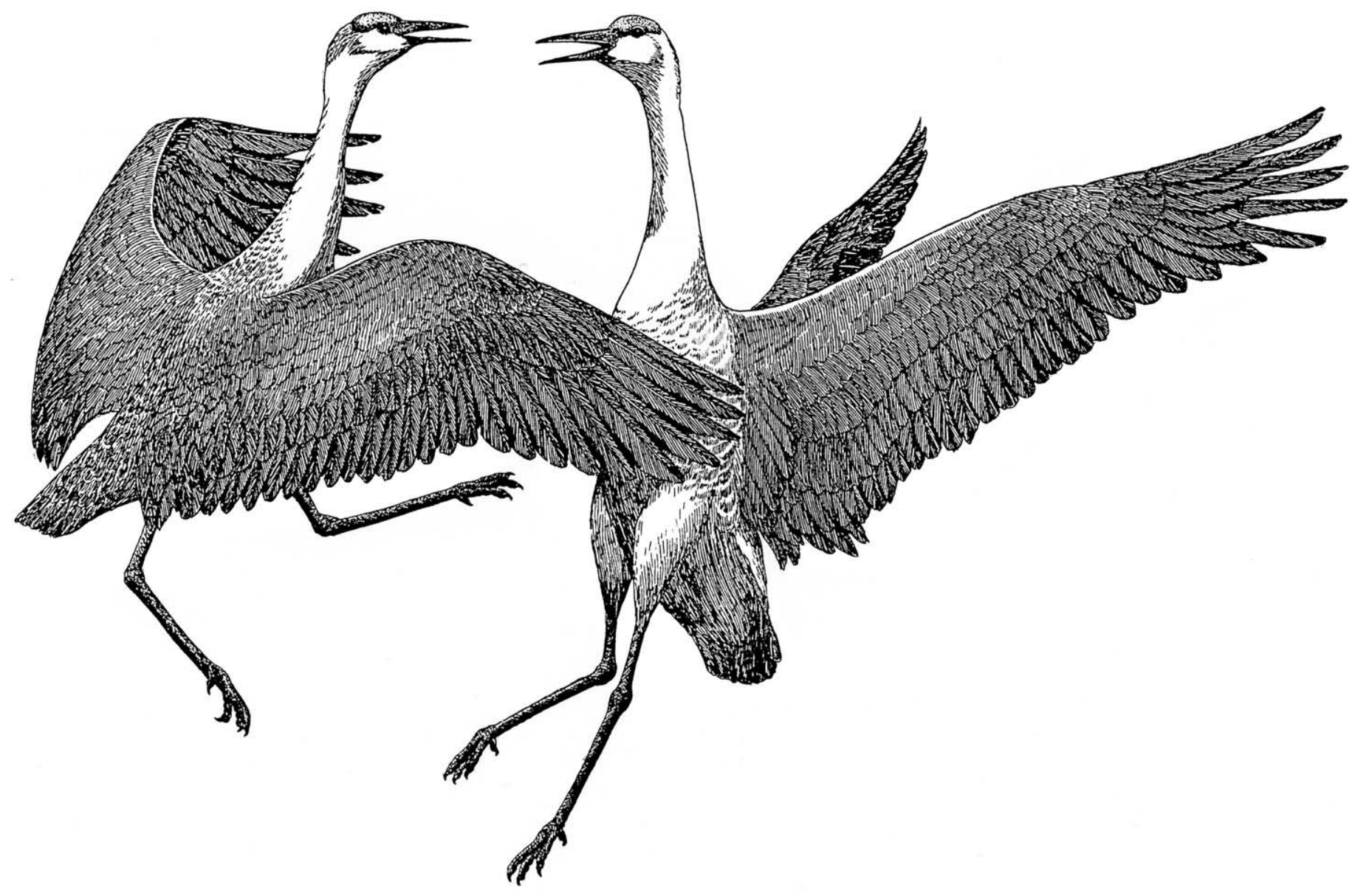

Two adult sandhill cranes sparring 


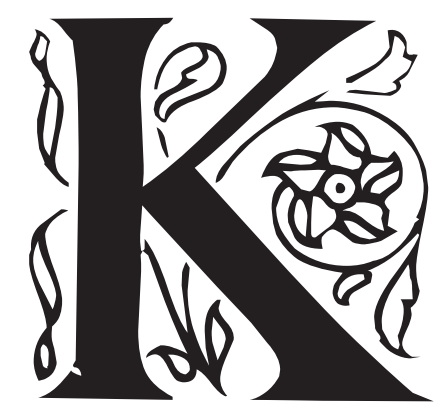

is for Kranich, which Germans named their own breeding crane.

Thousands winter in Spain, on the Andalusian Plain.

The most abundant crane of Europe is the common or Eurasian crane, which in many ways is the ecological counterpart to the North American sandhill crane. Like it, the common crane has been increasing in number and breeding distribution. It is better protected from "sport" hunters than the sandhill crane is in America, and its seasonal arrival is greatly anticipated as a harbinger of spring. Next to the sandhill cranes, it is the most abundant of the world's cranes, with recent population estimates of at least 700,000 birds. 


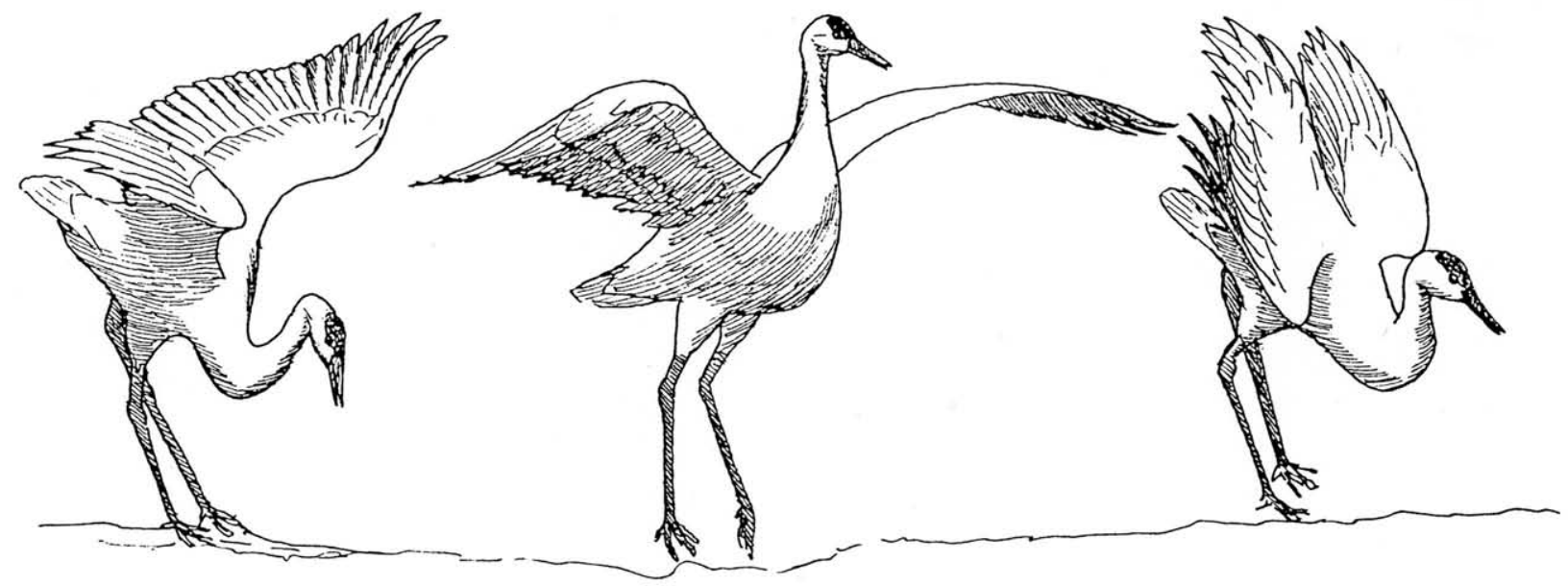

A
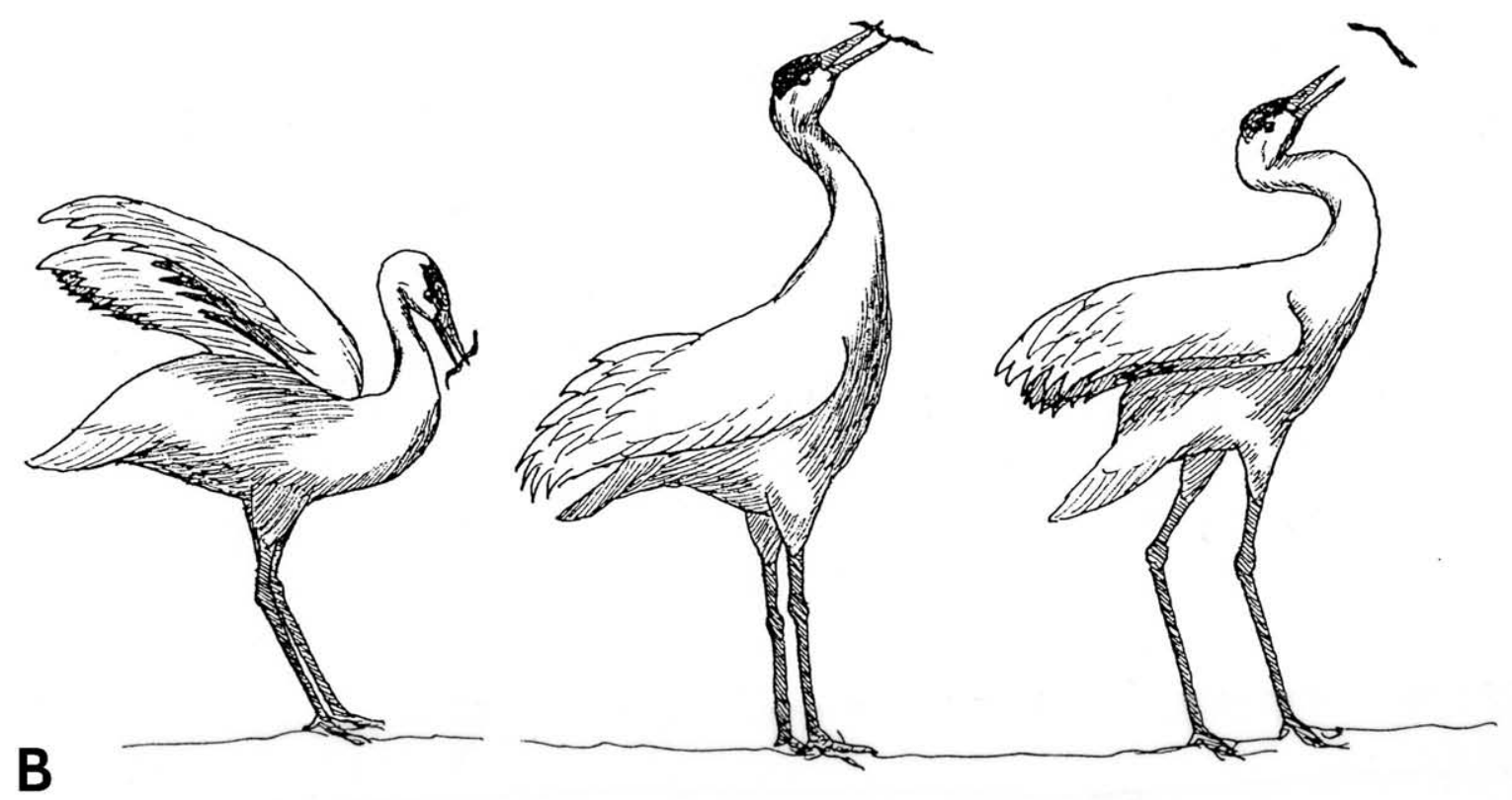

Sandhill crane bowing (A) and stick-tossing (B) display sequences 


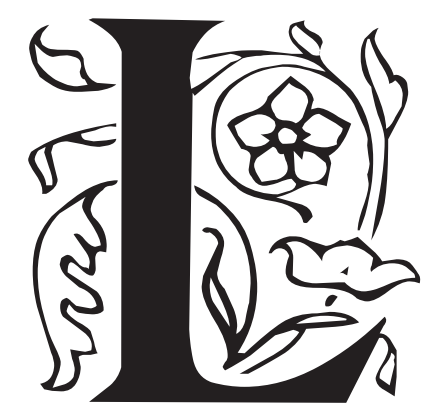

is for long lifespans, true wherever cranes roam.

Tame cranes were once valued as pets, long ago in ancient Rome.

The longevity of cranes is remarkable. Long lives are fairly common among all crane species. Even heavily hunted sandhill crane populations have often been found to include individuals at least 25 years old, and in captivity individual cranes have lived upward of 50 years. The most amazing example of crane longevity is a male Siberian crane that was captured in Russia as an individual of unknown age. The bird was eventually brought to the United States and exhibited in the Philadelphia Zoo for many years. Later, he was sent to the International Crane Foundation in Wisconsin. There he fathered offspring for many years, almost up until he died at an age at least in the mid-70s. 

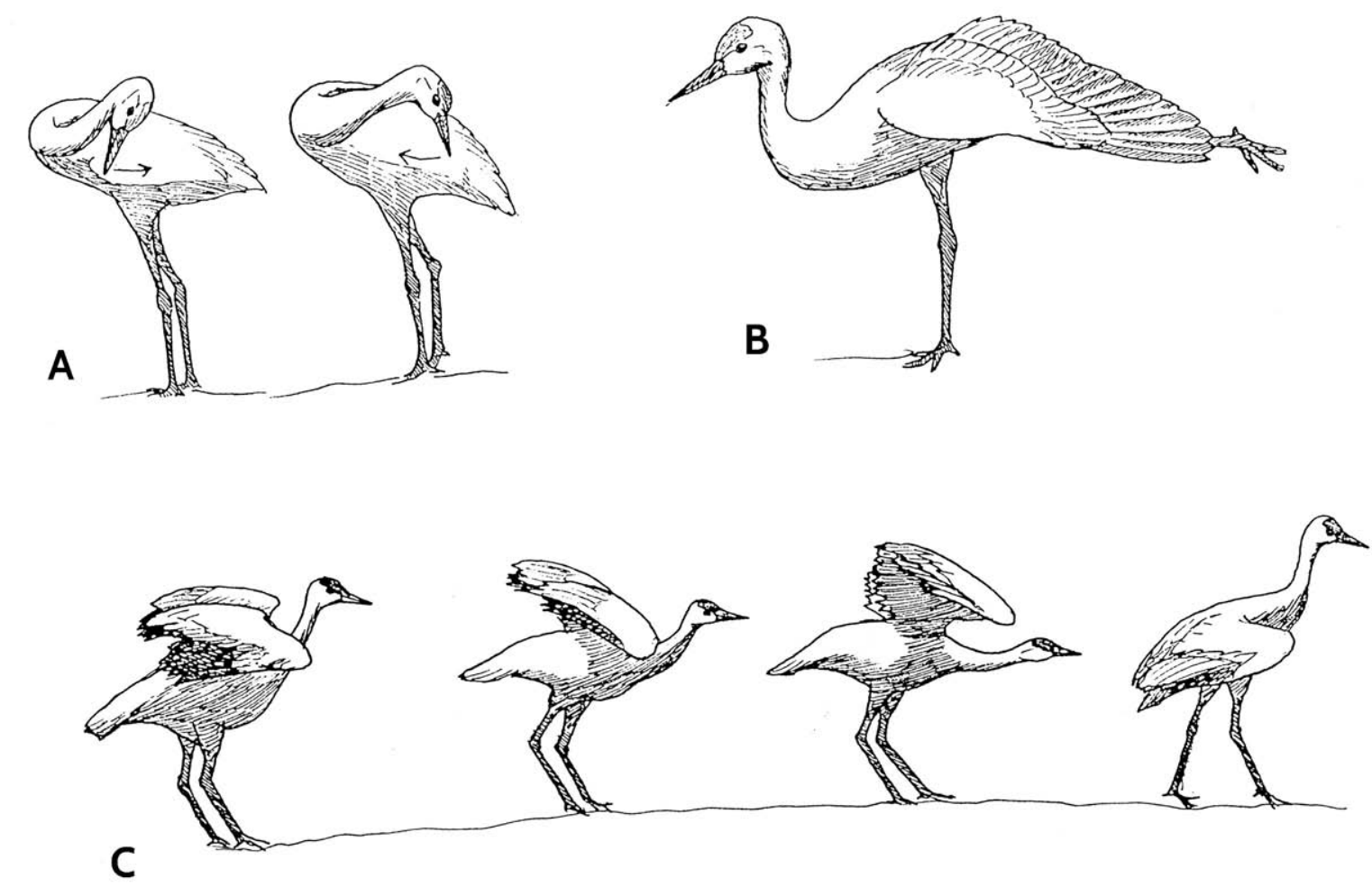

C
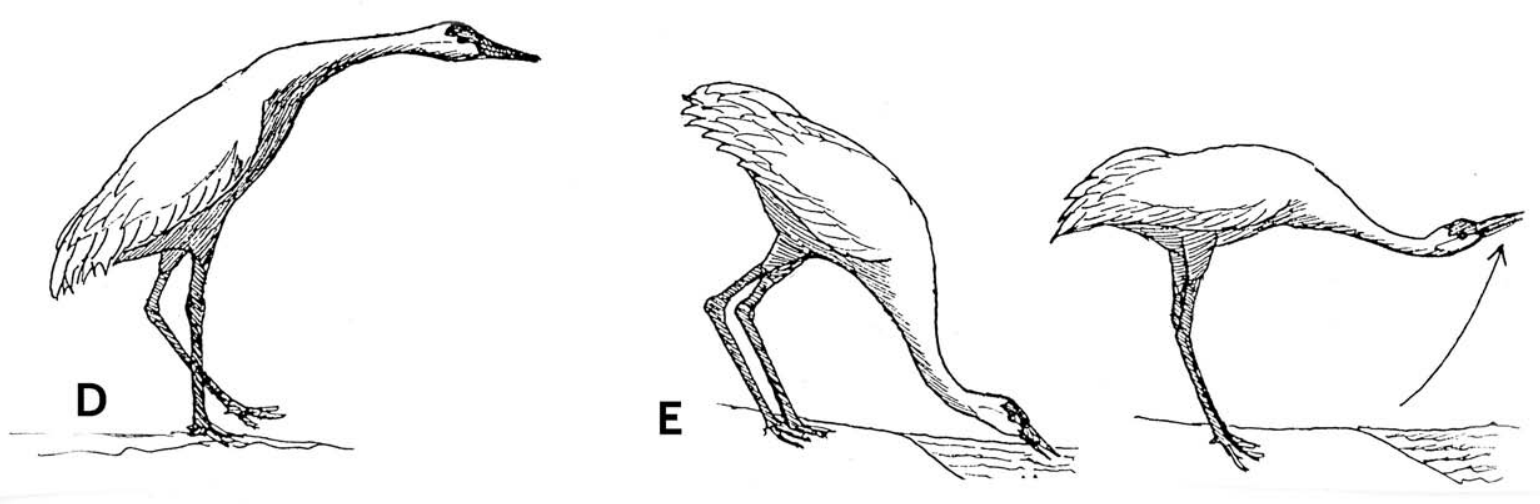

Sandhill crane preening (A), wing-stretching (B), bow-stretching (C), exhibiting flight-intention posture (D), and drinking (E) 


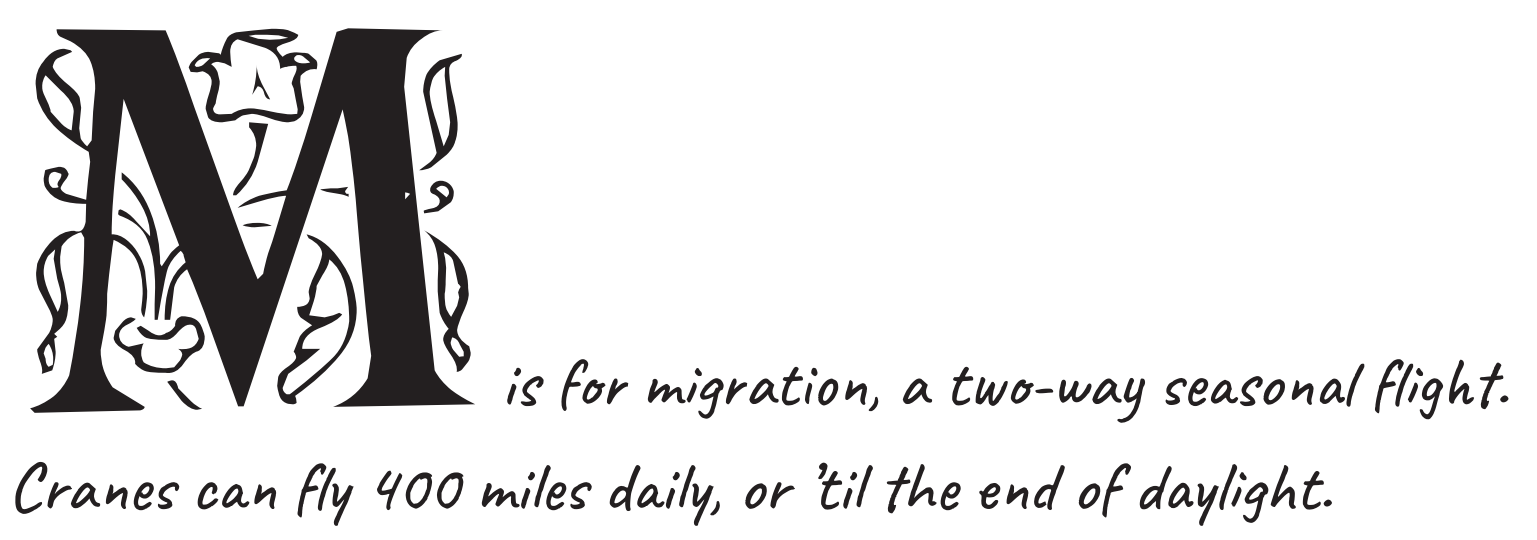

The smallest race of the sandhill cranes breeds on high-Arctic northeastern Siberian tundra and has a migration of nearly 4,000 miles to southeastern Arizona. These transcontinental migrations require several months to complete. Meanwhile, the much larger southernmost sandhill crane populations, such as those in Florida, Mississippi, and Cuba, are nonmigratory. The whooping crane's longest migration route-from Wood Buffalo National Park in Canada's Northwest Territories to Aransas National Wildlife Refuge in Texas-spans about 2,500 miles. During spring, this entire migration might be completed in as little as 9 days but usually requires about 16 to 17 days. The whooping crane's fall migration is much slower and often takes about a month to complete. 


$$
r^{1}
$$




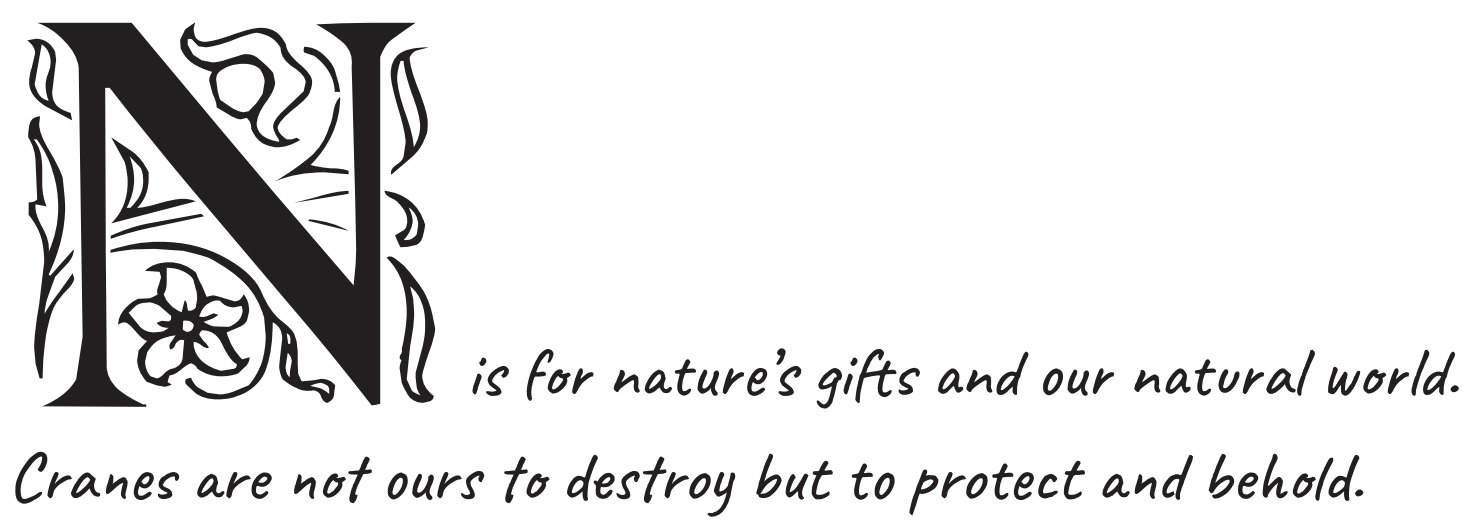

Of all the countries in the world, the United States has long been a leader in conservation of wildlife, even though in earlier times we have let slip from the world of living things such once-common birds as the great auk, the Labrador duck, the passenger pigeon, the ivory-billed woodpecker, and (probably) the Eskimo curlew. That is why, when the US Fish and Wildlife Service announced an "experimental" hunting season on sandhill cranes in 1960, I was painfully sickened. Like many other government programs, it has since gotten out of control and firmly entrenched, with more than 50,000 sandhill cranes now being shot annually for "recreation." This number excludes the unknown additional thousands of birds that are wounded and left to die. Crane hunting is now apparently about as popular as burning heretics at the stake was in medieval times. It is, in fact, so popular that many commercial cranehunting operations exist for people's comfort and ease in killing as many cranes as are allowed, regardless of the customers' hunting skill. 


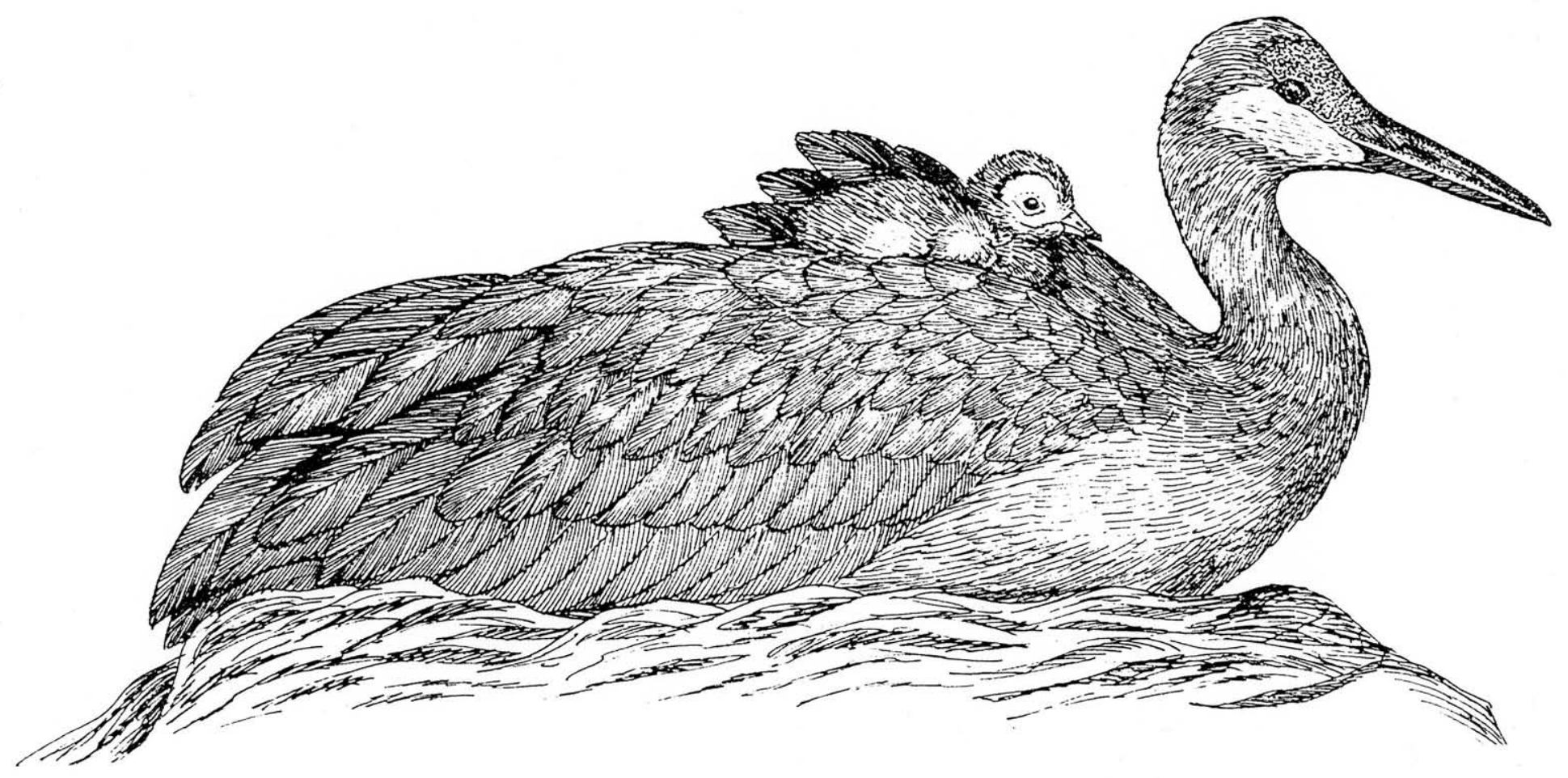

An incubating sandhill crane with a newly hatched chick on its back 


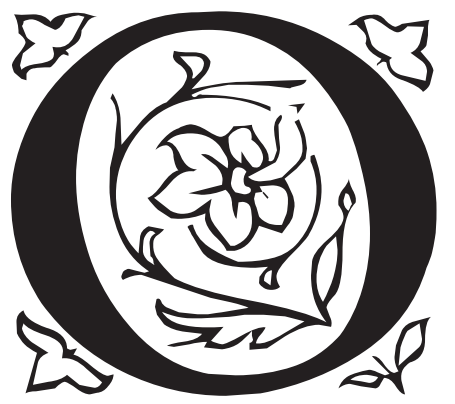

is for "Oh my gosh," a commonly heard shout

When first seeing cranes; it's a wondrous occasion, no doubt.

Many experiences in life are memorable, but to me one of my most powerful nature memories is seeing my first wild sandhill cranes. This occurred on a late March afternoon in 1962 while driving a university van full of undergraduate ornithology students on a field trip to the central Platte River. After several hours of driving, we suddenly saw a flock of sandhill cranes peacefully foraging in a wet meadow along the Platte south of Elk Creek. Although we had been hoping to see cranes and had searched all day for them, the actual event left me almost in tears. I felt I had been given a gift of unspeakable value and knew it would be forever etched in my mind. Since then, I have had many other wonderful adventures with sandhill and whooping cranes from the Alaskan and Canadian Arctic tundra to cactus-lined Arizona playas, but none overshadow this powerful memory. 


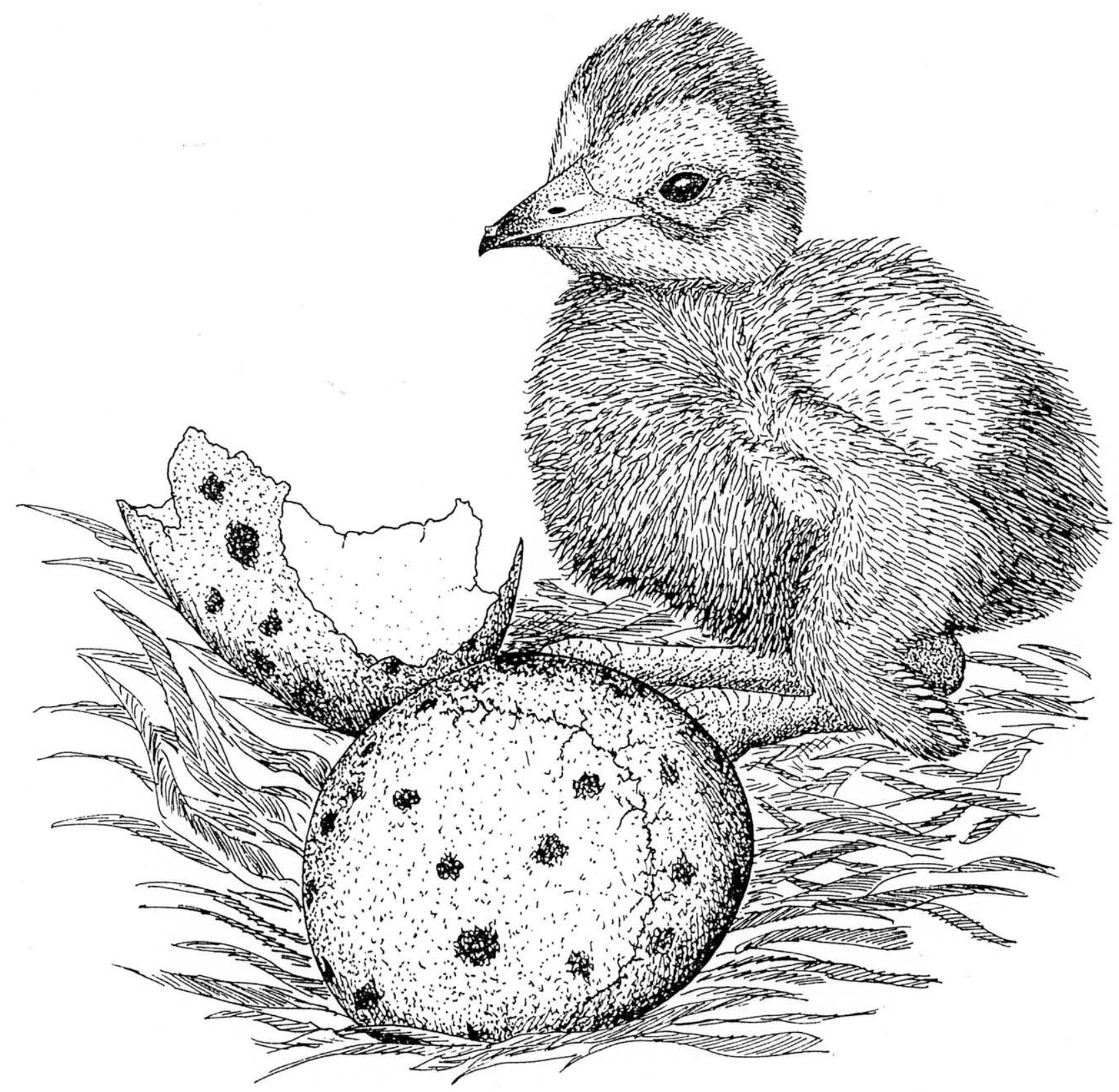

A newly hatched sandhill chick and a hatching egg 


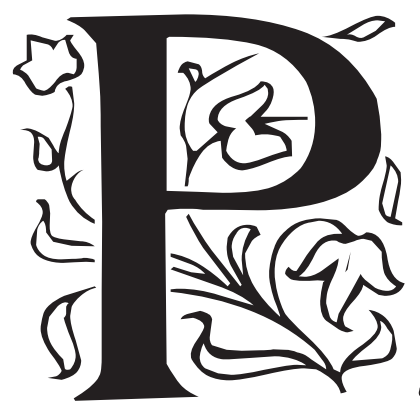

is for the Platte, Nebraska's own river of dreams, Flowing above sand from the Rockies and fed by cold glacial streams.

The Platte River was named for its placid ("flat") lower reaches rather than its torrential mountain headwaters in Colorado and Wyoming. Although many tourists might prefer a mountain background for their river scenes, they have probably never seen the Platte at dawn with 50,000 or more cranes lining its banks, bars, and sandy islands, all saluting the rising sun with a deafening chorus of apparent joy for the approaching day. At such times I almost dare not to breathe or move a muscle, in fear of making a sound that might alarm the birds into flight. Eventually the birds take flight anyway, amid a cacophony of crane music, soon leaving behind only a few gray feathers on the water and a nearpain in the heart of the viewer for having been witness to such a glorious sight.

34 


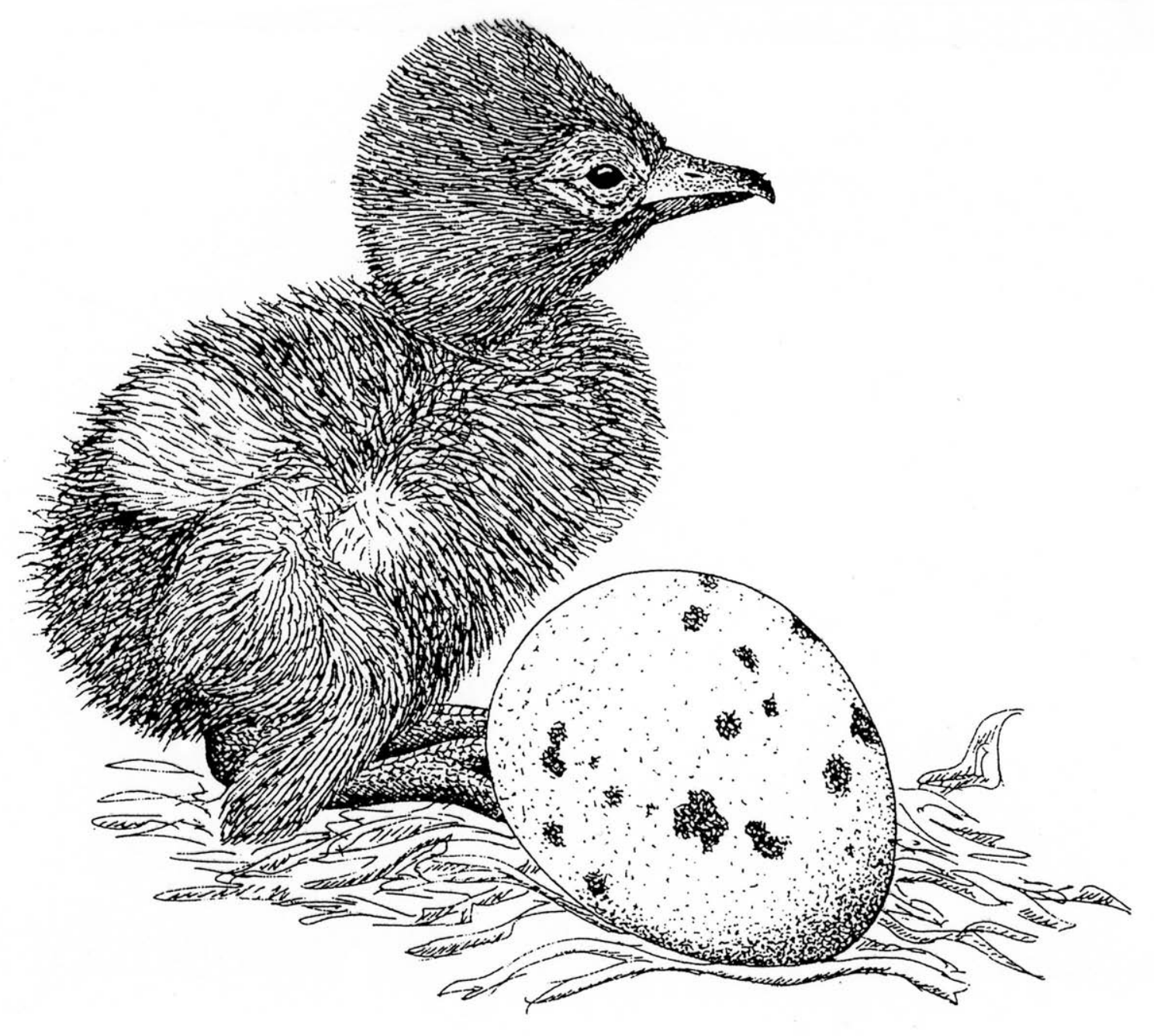

A newly hatched sandhill chick and an infertile egg 


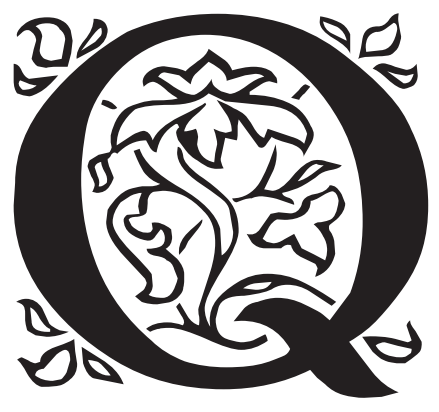

is for Quivira, an ancient mythic city of gold.

It's also a bird refuge in Kansas, rich in bugs, mud, and leaf mold.

Of the many national wildlife refuges in the Great Plains, Quivira in south-central Kansas is one of my favorites. Its 22,000 acres include 7,000 acres of shallow wetlands that range from freshwater to alkaline, with associated variations in wetland vegetation. For such reasons, it attracts a great diversity of wildlife, including more than 350 documented species of birds. Up to about 800,000 waterfowl visit the refuge in fall, and 200,000 in spring, along with nearly 40 species of ducks, geese, and swans. The refuge also seasonally hosts hundreds of thousands of sandhill cranes, has regular visits by as many as 61 migrating whooping cranes, and even provides some sightings of the extremely rare (in this country) Eurasian crane. Together with the central Platte River valley, Quivira is the most important crane stopover point between Texas and the Canadian border. 


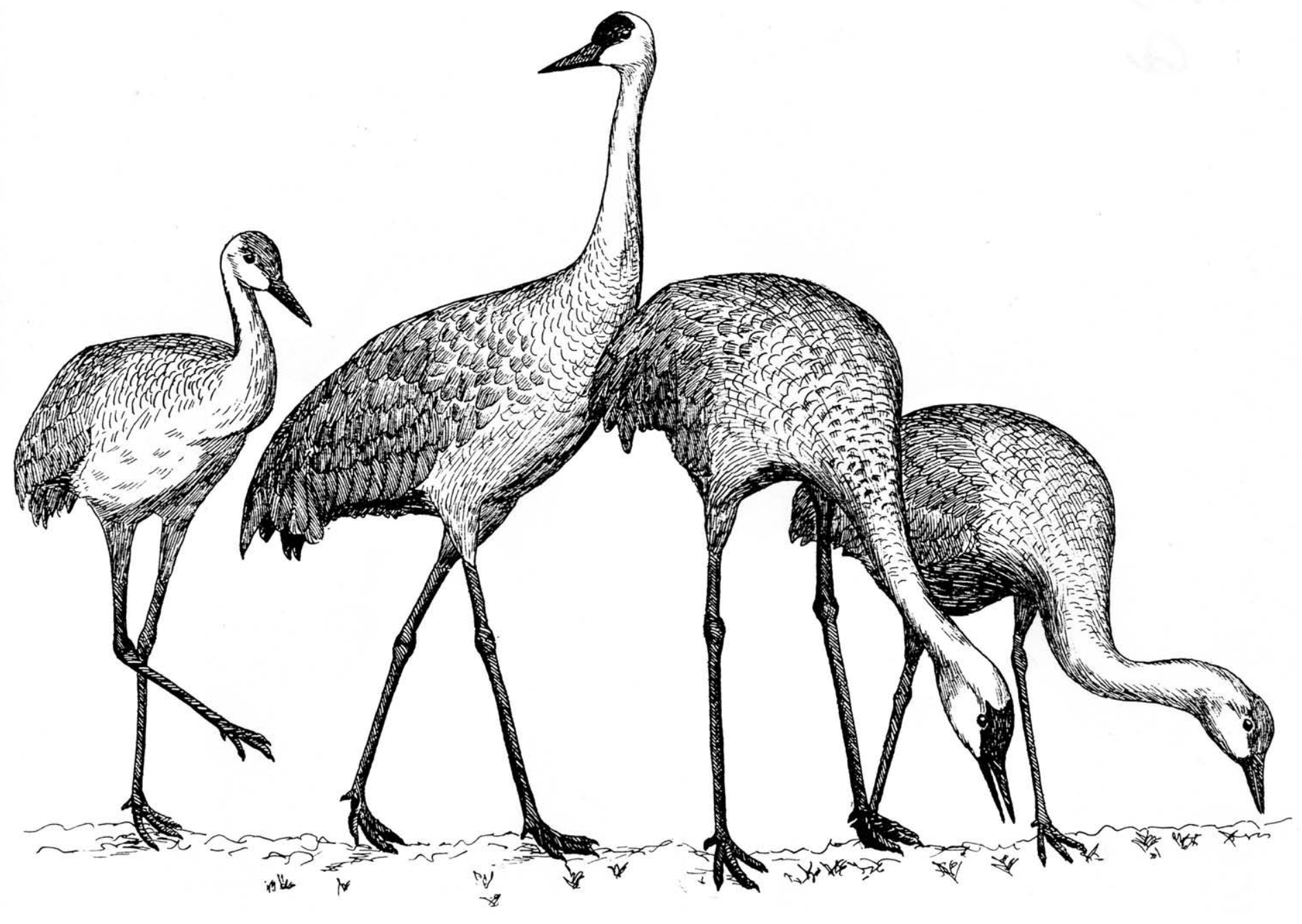

A sandhill crane pair with two juveniles 


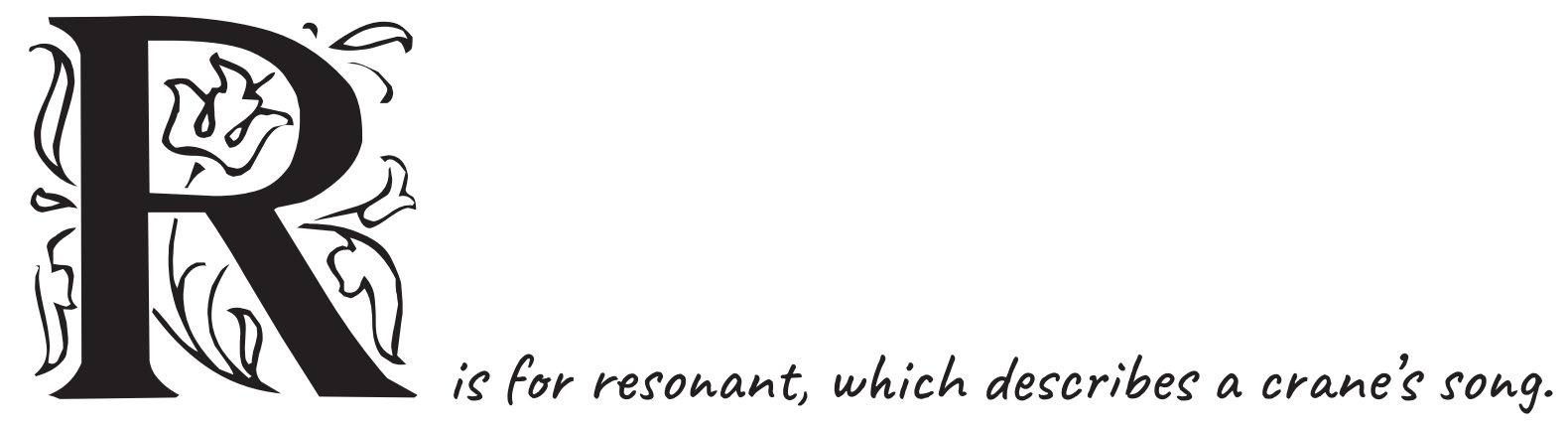

Adults have a very long windpipe, coiled like a French horn.

The resonant voices of both American crane species depend mostly on the structure of their windpipe, which, as the birds mature, elongates and penetrates the vertical keel of the breastbone. As the windpipe lengthens, curves back, and variously coils, the cranes greatly improve their effectiveness in producing harmonic overtones. Such vocal complexity allows each bird to generate sounds that are individually unique and probably recognizable to both pair and family members. 


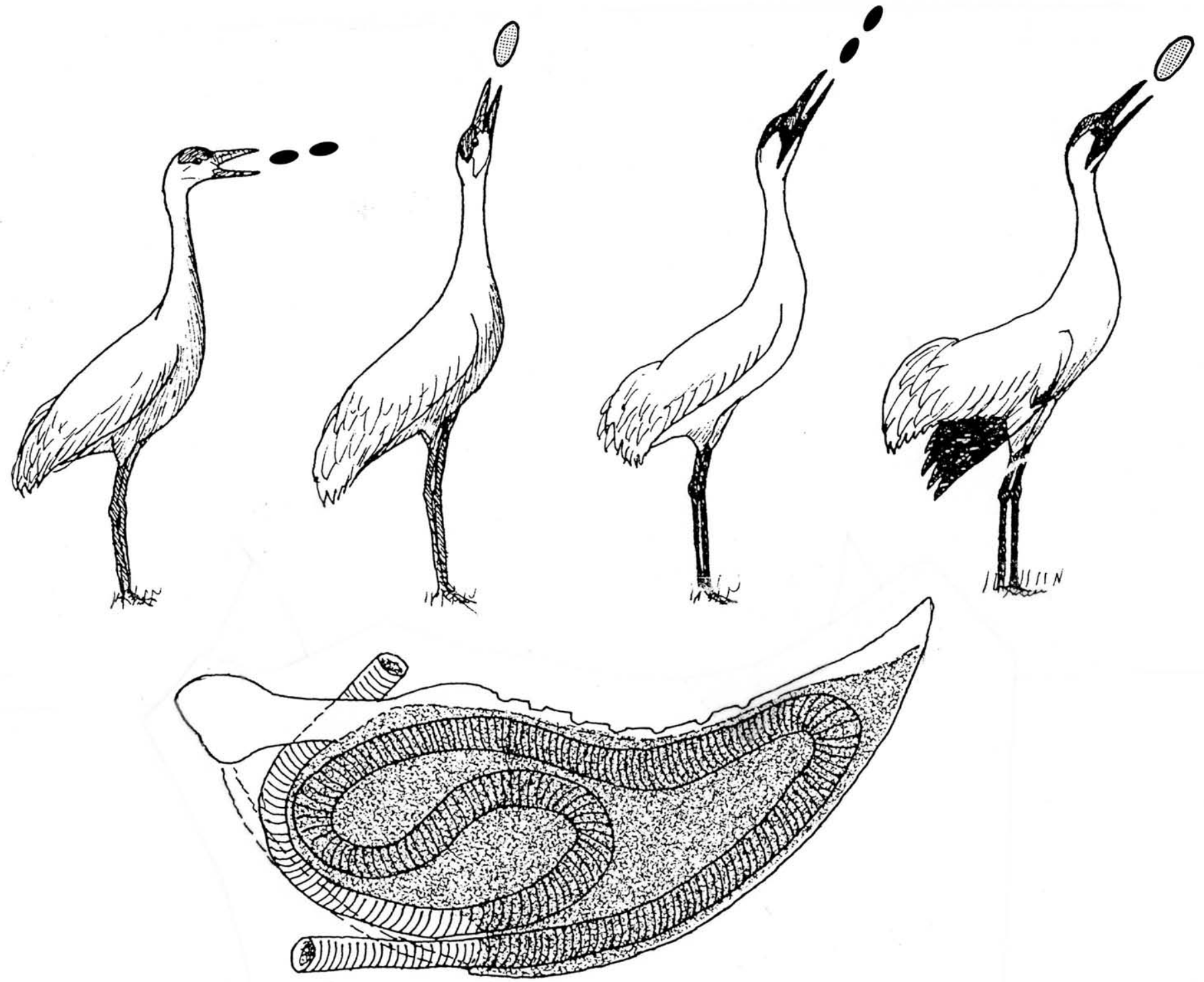

Unison calling by sandhill crane (left) and whooping crane (right); the balloons indicate call cadence by females (black) and males (stippled). The breastbone and internal windpipe of an adult whooping crane are also shown. 


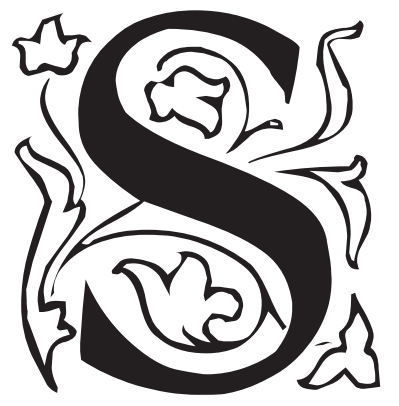

is for sandhill, describing both a crane and a sandy space.

In Nebraska, the Sandhills region is a near-magical place.

The 19,000-square-mile region of the rather sparsely vegetated Nebraska Sandhills covers nearly a quarter of the state's area and includes thousands of generally small and shallow wetlands that once supported breeding sandhill cranes until about 1900. Now the small number of sandhill cranes that regularly breed in the state nest mostly elsewhere, on a few rather remote wetlands of northern, south-central, and western Nebraska. The birds are so secretive during breeding that in most cases they go unobserved until the well-grown young appear with their parents. 


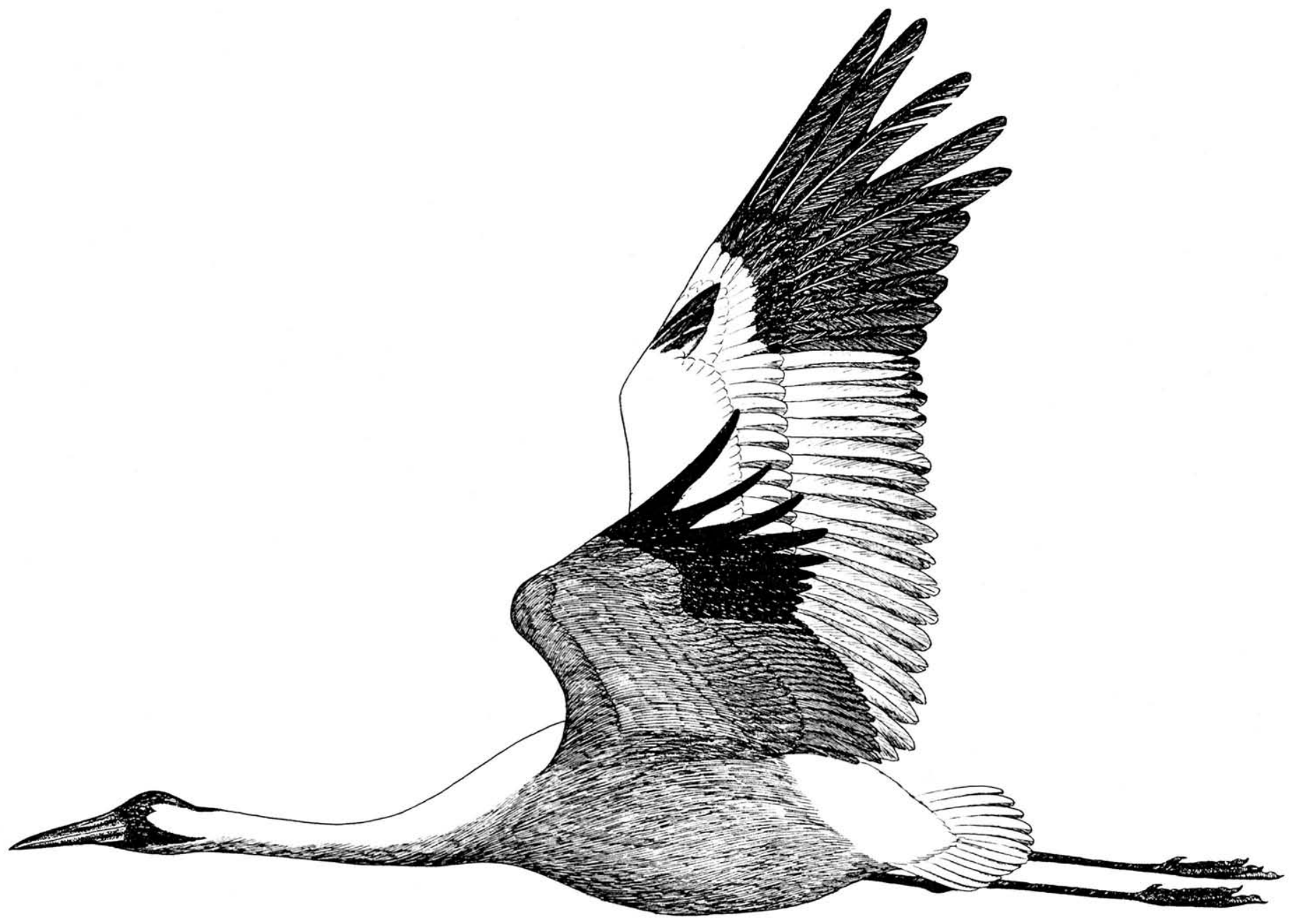

An adult whooping crane in flight 


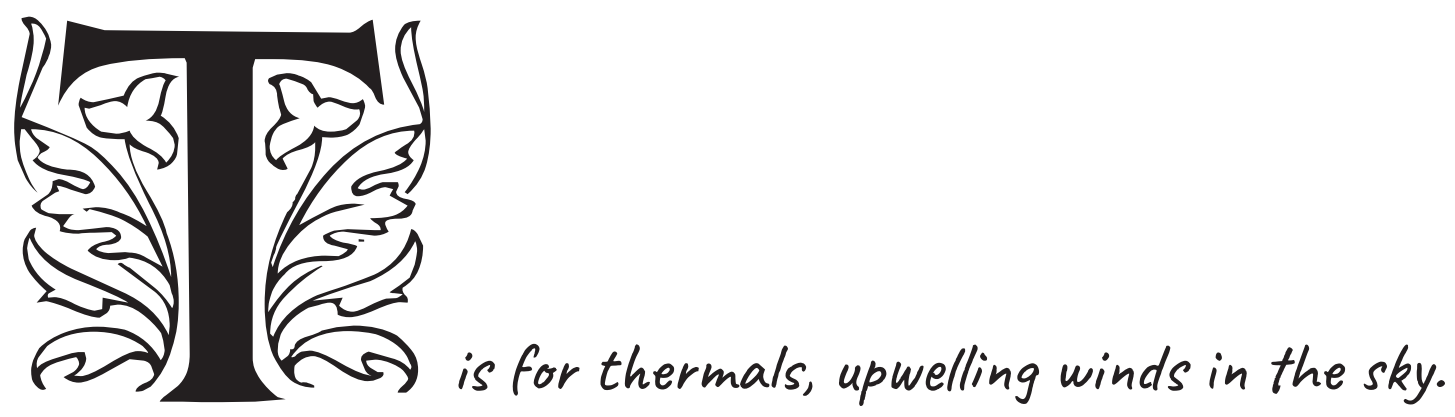

They can lift broad-winged cranes to more than 20,000 feet high.

Thermal wind currents are produced by the sun's warming of the earth, which then radiates heat and warms the air above. As it warms, the air becomes less dense and rises above surrounding cooler air. A column of rising air is thus produced, which cranes and other soaring birds, such as hawks, can exploit and rise vertically upward for thousands of feet on their extended wings, without using any of their own energy to gain altitude. During migration cranes often seek out such thermals to gain enough height to allow them to then glide for many miles before having to repeat the process. 


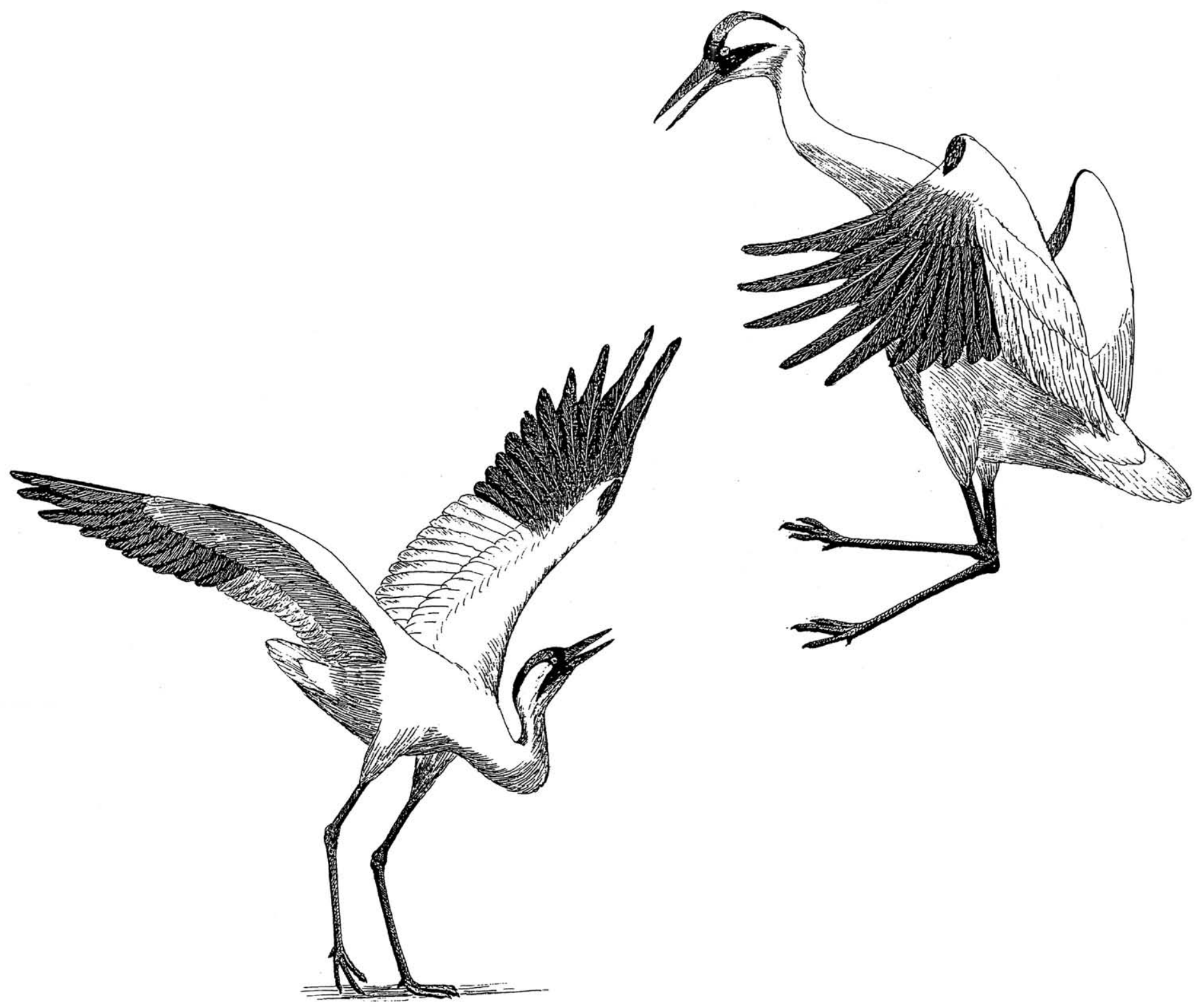

A pair of whooping cranes dancing 


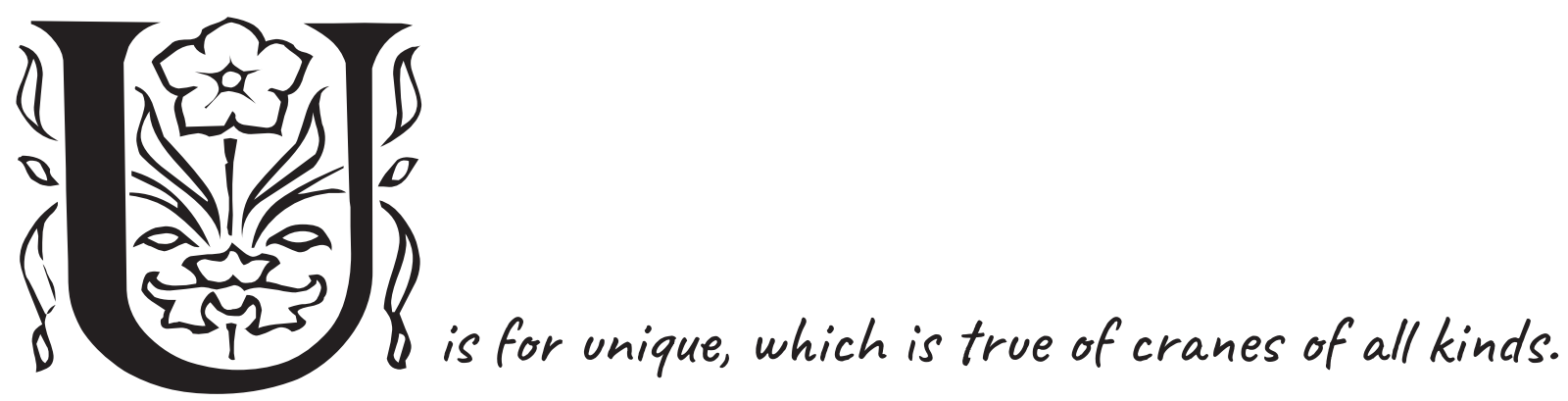

There are 15 in the world; seeing any is a feast for the mind.

Cranes are unique in many ways, such as their complex dancing behavior and associated pair-bonding and pair-maintenance behavior, which helps to retain family and flock coherence, transmit complex migratory "traditions" across generations, and improve both individual and flock survival. When viewing cranes, a person should recognize that he or she is seeing not "a mere bird" but rather a creature of real intelligence whose ancestral history goes back in time at least ten times that of humans. Their ancestors survived countless human wars and pandemics and experienced the rise and disappearance of entire human civilizations with supreme indifference. 

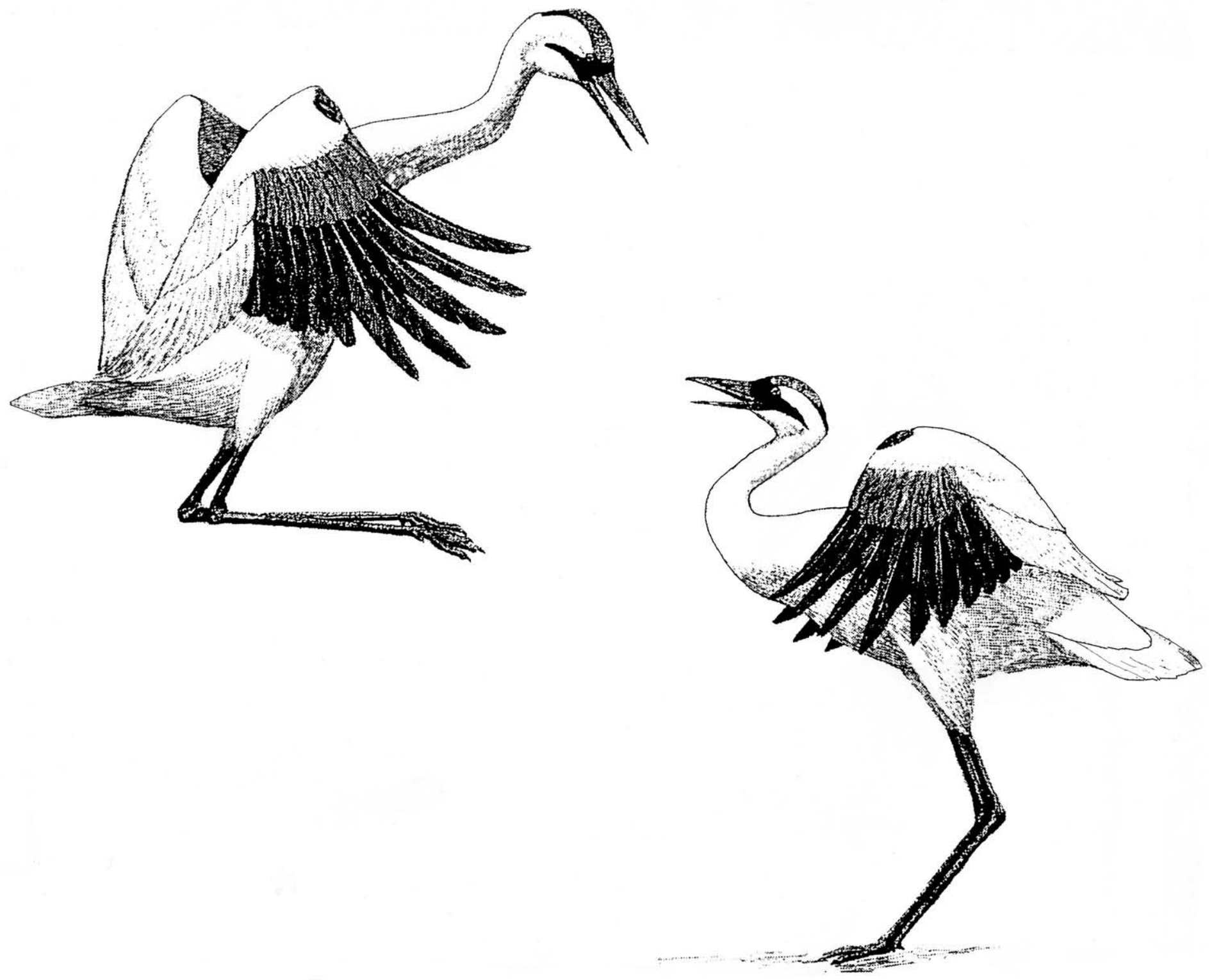

A pair of whooping cranes dancing 


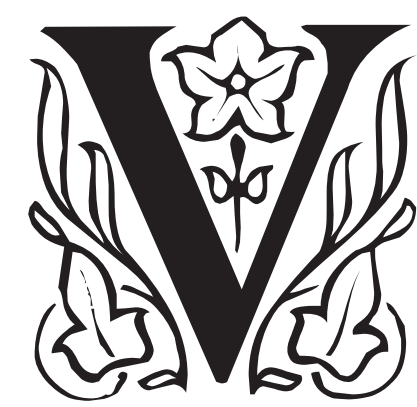

is for "vuluerable," a term for birds becoming ever rarer.

The whooping crane is "endangered" and was nearly lost forever.

The term "vulnerable" is used by various conservation agencies to describe those species that are declining in number and, unless the current trend changes, might become "endangered." One major international conservation group (the International Union for Conservation of Nature) lists seven of the world's 15 crane species as "vulnerable," three as "endangered," one as "critically endangered," and only three as of "least concern." 


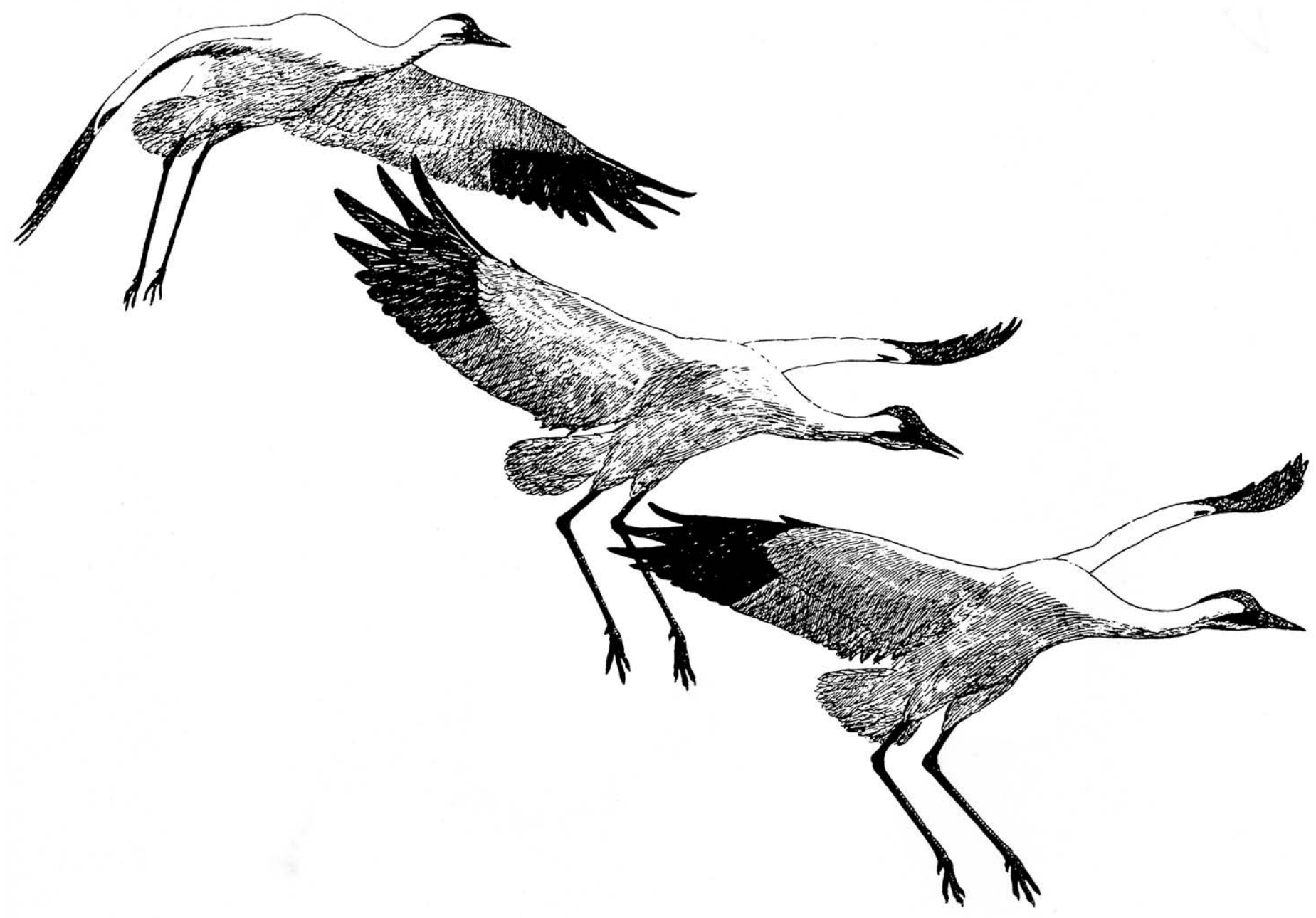

Three whooping cranes landing 


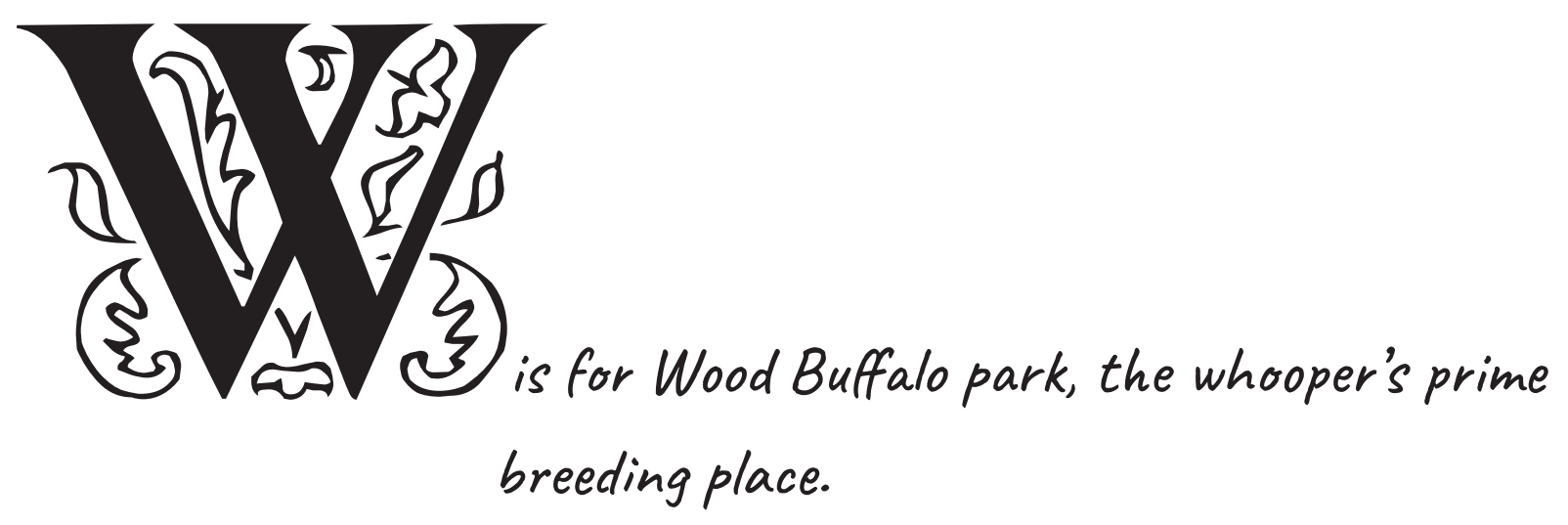

It's a refuge in Canada, where cranes can nest and leave not a trace.

As of 2021, only about 800 whooping cranes exist in the world. They include about 700 living free in the wild and the rest living in captivity. In 2020, the wild migratory populations included about 500 in the historic Canada-Texas flock and about 100 in a Wisconsin-Florida flock. The latter was initiated by training young whooping cranes to use a migration route from a rearing area in central Wisconsin (Necedah National Wildlife Refuge) to wintering grounds in Florida. Nonmigratory populations include a recent experimentally reintroduced flock in southern Louisiana that is now approaching 100 birds, plus fewer than 10 remnant individuals from a failed reintroduction effort in central Florida that ended in the early 2000 s. 


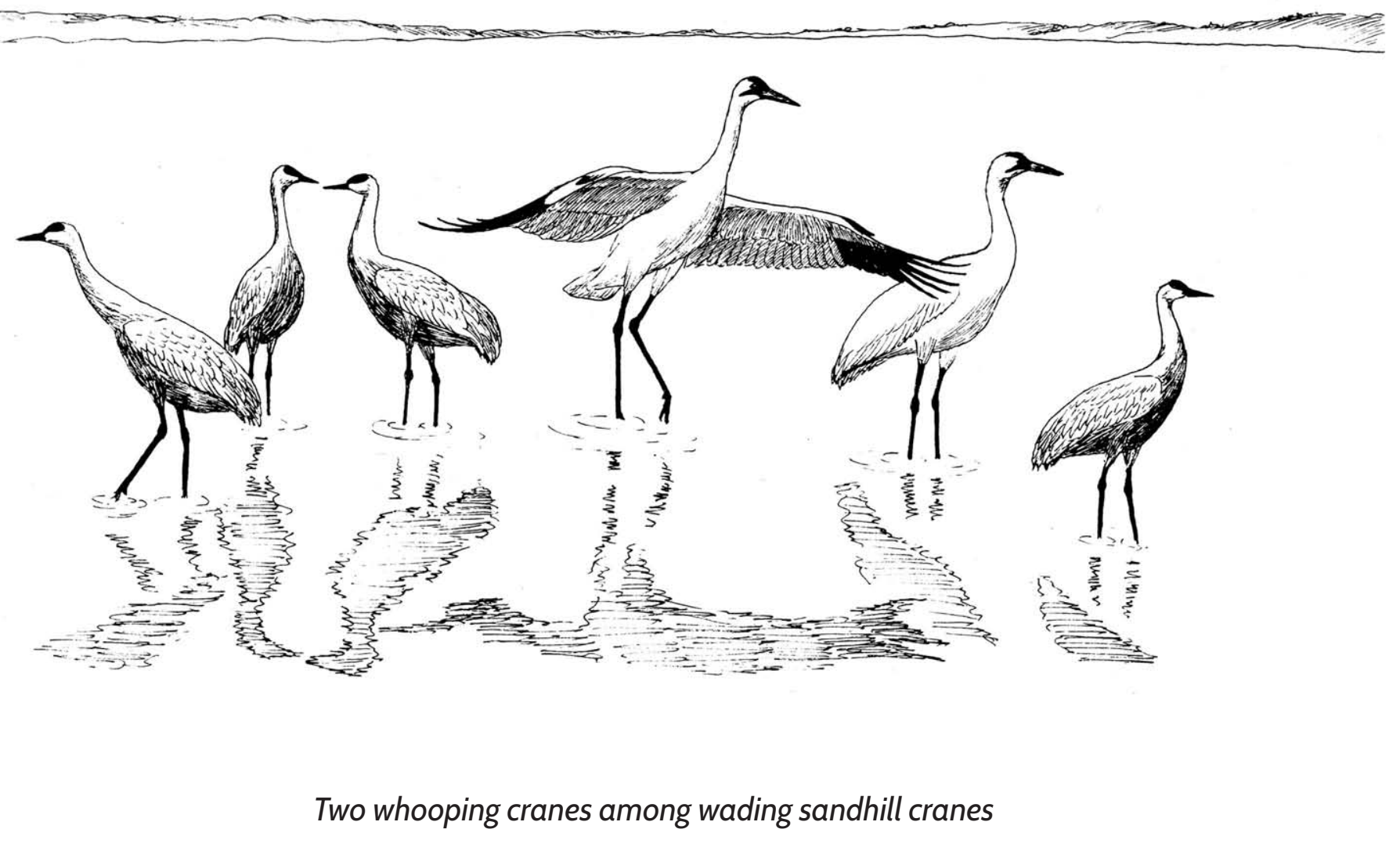


is for a crane word that is yet to be found.

If you can think of a good one, I will pass it around.

The letter $\mathrm{X}$ has begotten very few useful biological words, but one is Xerces. It is the scientific name of a small California butterfly that is now extinct because of urban development in its habitat. Humans are far too busy with their individual lives to worry about the fate of a single butterfly. However, extinct plants and animals offer a warning of dangers to humanity from overpopulation, resource waste, increased greenhouse gases, a gradually heating atmosphere, and associated global warming. 


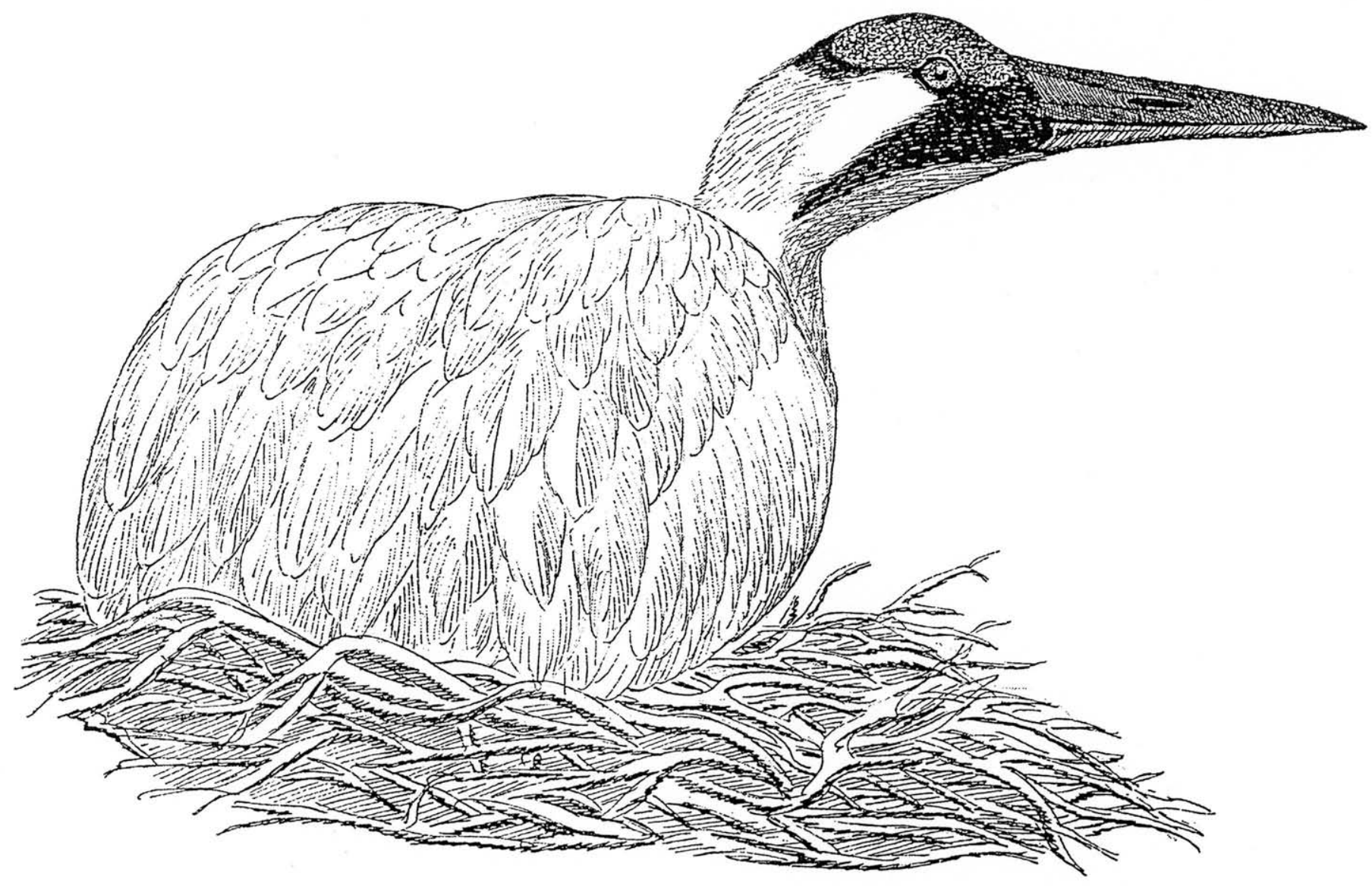

An incubating whooping crane 


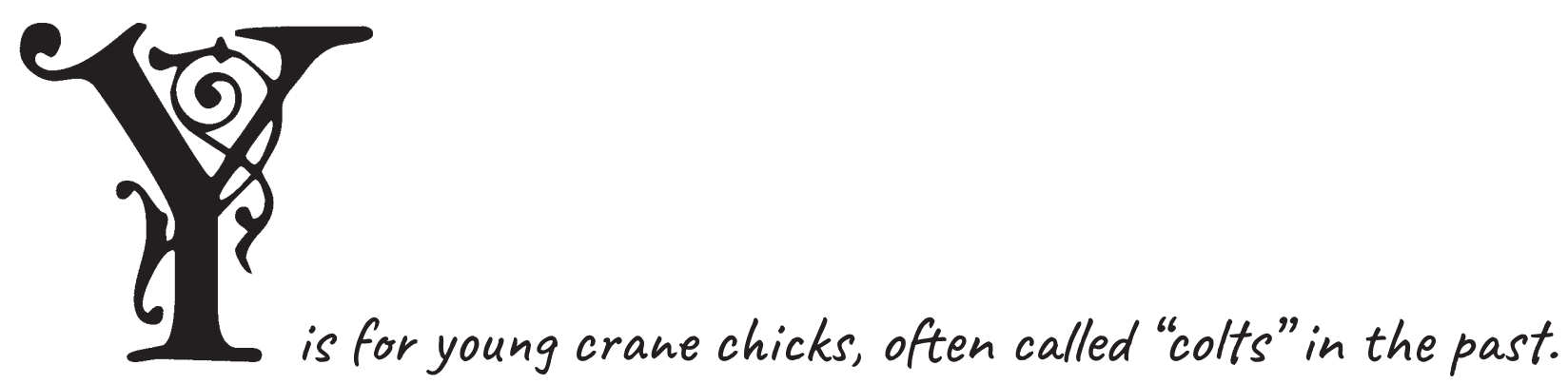

They are as golden as palomino ponies and can run nearly as fast.

Young cranes go through a series of changes in plumage and appearance during their first year of life. They are hatched in a golden-cinnamon downy plumage that is waterproof and allows them to swim easily on water. The chicks grow fast, and within a month are twice their height at hatching. By 75 days they are about 80 percent of adult height and are developing juvenile body feathers on the wings and hindquarters. Fledging occurs at 80 to 90 days in whooping cranes and at 60 to 70 days in sandhill cranes. At three months of age, the juvenile cranes are nearly as tall as the adults and are ready to undertake the long fall migration. By about a year of age, their windpipes have lengthened, and their voices shift from the "baby" whistled voices of chicks to produce more adultlike and throaty calls. Then they also begin to lose their crown feathers and slowly develop bare, pink-skinned foreheads. 


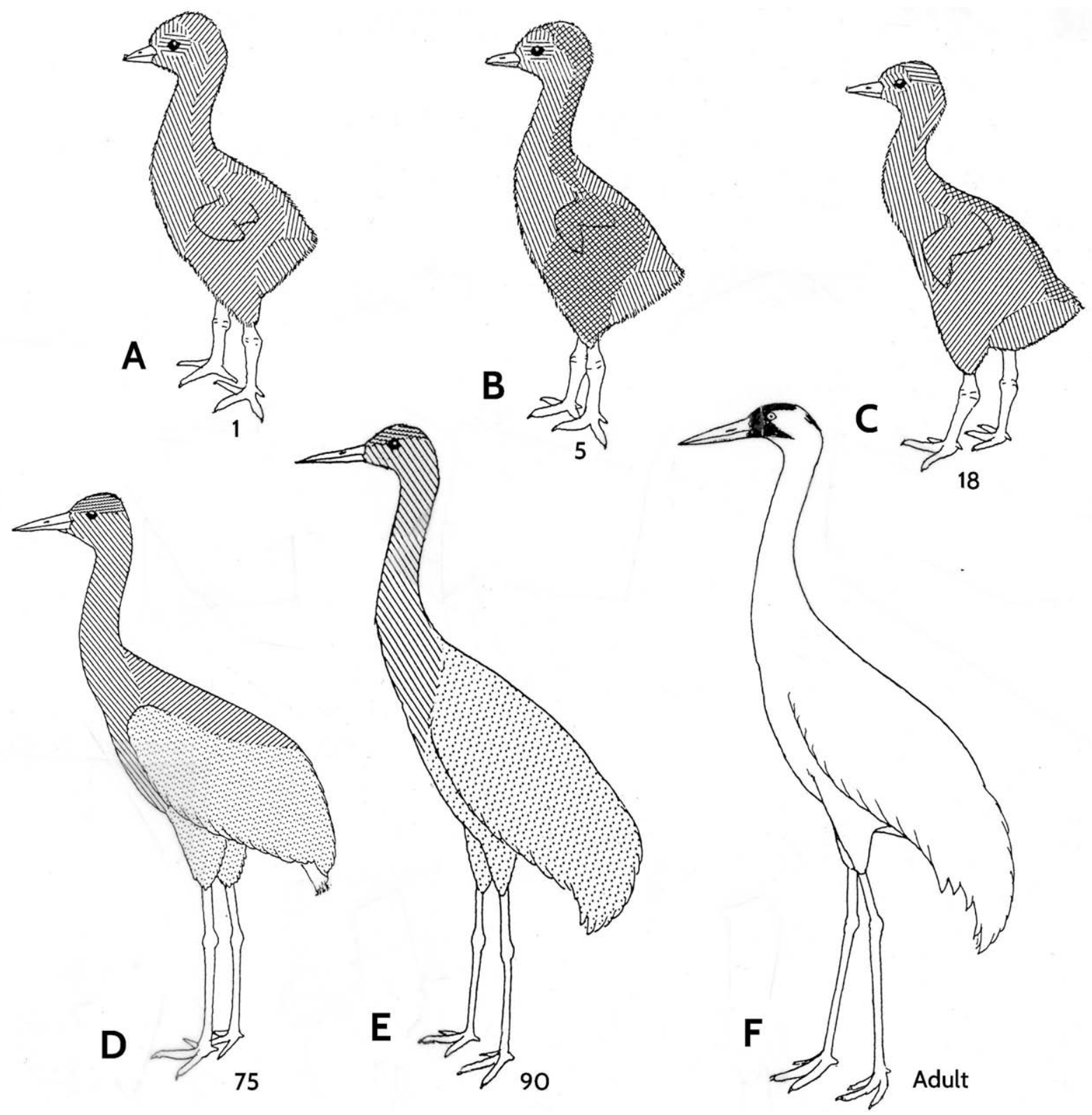

Growth development in whooping cranes at 1, 5, 18, 75, and 90 days, compared with adult 


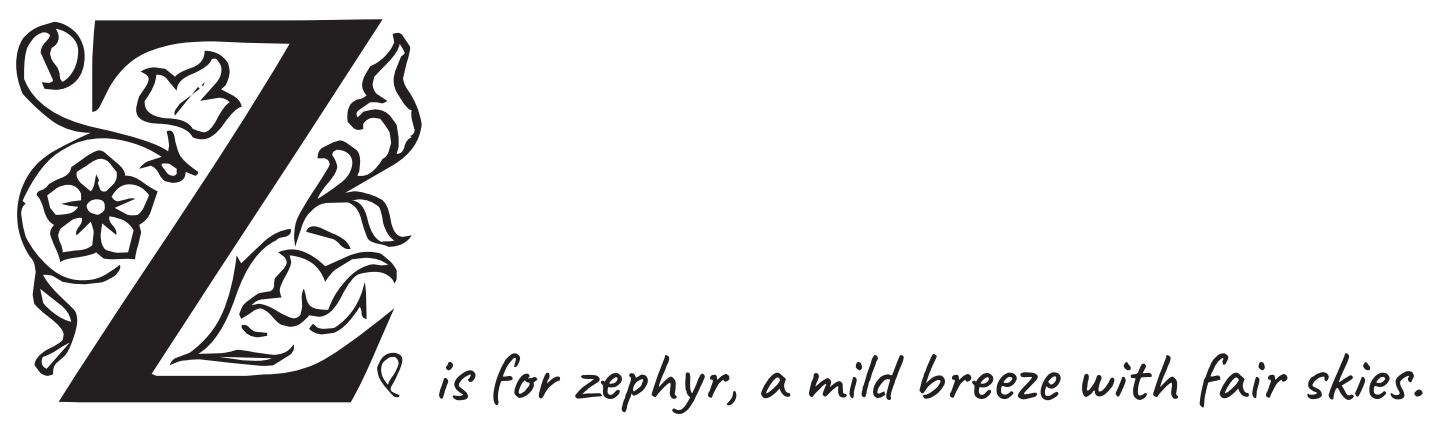

You might then see migrant cranes, if you just open your eyes.

The term zephyr is named after Zephyr, the Greek god of the west wind, which in the United States is usually associated with mild weather and sunshine. That is the condition common during spring bird migration and is a time to celebrate the end of the north winds of winter. Cranes often migrate north on mild south winds and sunny skies abundant with thermals, which are often marked by high billowing cumulus clouds that form on their tops as the air cools and atmospheric moisture condenses. For me, seeing a vortex of cranes slowly rising above the Platte on a warm thermal in early April instills a bittersweet mixture of profound happiness for having one last view of them and sadness that they are destined to face their individual fates on some distant tundra wetland thousands of miles away and will be gone from my life until the cool north winds of autumn arrive again. 


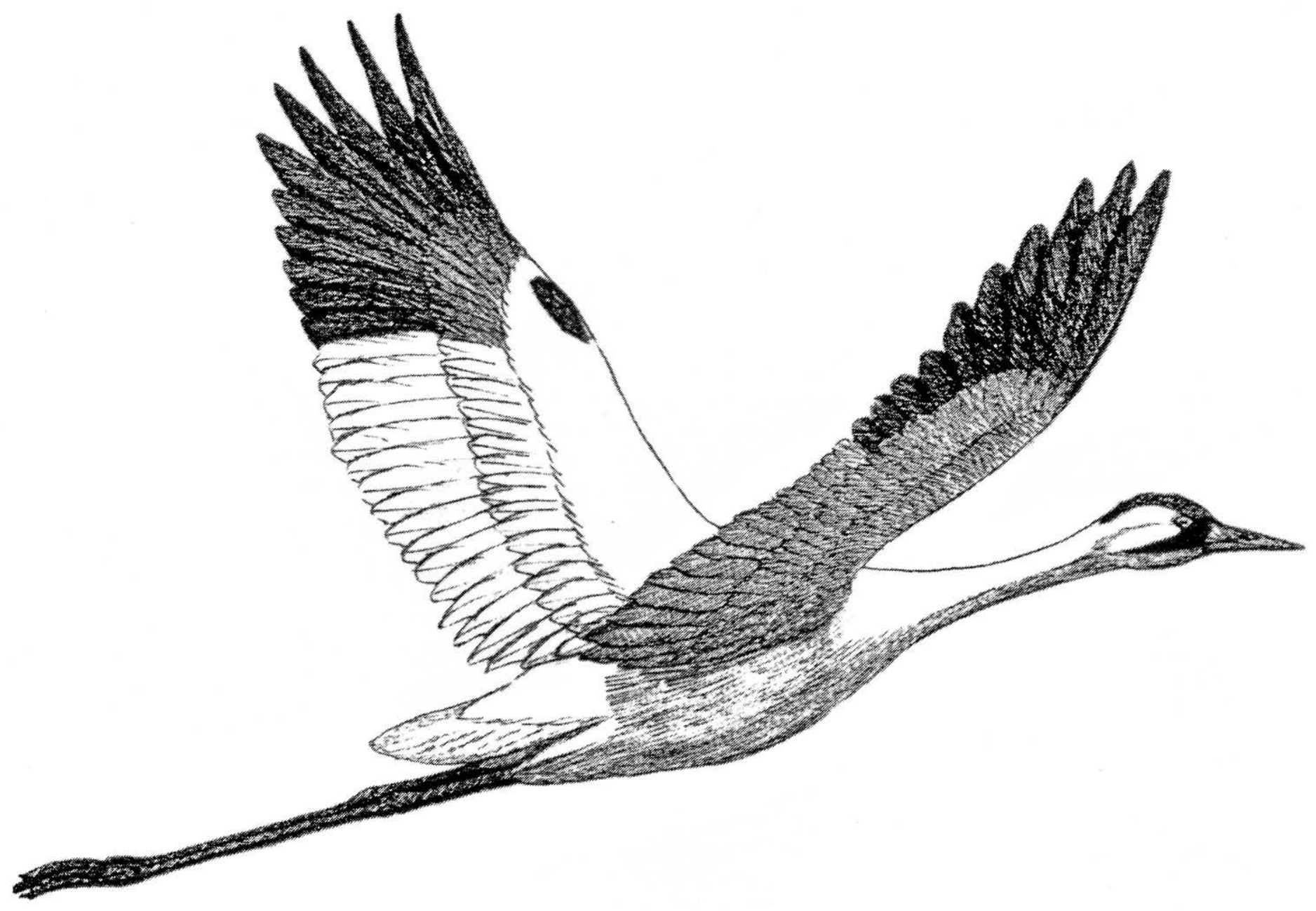

Adult whooping crane in flight 


\section{References}

Archibald, G. 2016. My Life with Cranes: A Collection of Stories. Baraboo, Wl: International Crane Foundation. 160 pp.

Happ, C. Y., and G. Happ. 2017. Sandhill Crane Display Dictionary: What Cranes

Say with Their Body Language. 2nd ed. Wildlife and Nature Identification

Series. Safety Harbor, FL: Waterford Press. (Fold-out guide)

Hughes, J. M. 2008. Cranes: A Natural History of a Bird in Crisis. Buffalo, NY:

Firefly Books. 256 pp.

Johnsgard, P. A. 1981. Those of the Gray Wind: The Sandhill Cranes. New York: St.

Martin's Press. $150 \mathrm{pp}$.

—. 1983. Cranes of the World. Bloomington: Indiana University Press. 256

pp. See also https://digitalcommons.unl.edu/bioscicranes/24/

- 1991. Crane Music: A Natural History of American Cranes. Washington,

DC: Smithsonian Institution Press. 136 pp.

- 2007. A Guide to the Natural History of the Central Platte Valley of

Nebraska. Lincoln: University of Nebraska-Lincoln Digital Commons and Zea Books. 156 pp. https://digitalcommons.unl.edu/biosciornithology/40/

- 2008. The Platte: Channels in Time. Lincoln: University of Nebraska Press. 176 pp.

-2011. Sandhill and Whooping Cranes: Ancient Voices over America's

Wetlands. Lincoln: University of Nebraska Press. 155 pp.

- 2015. A Chorus of Cranes: The Cranes of North America and the World. Boulder: University Press of Colorado. 242 pp. 
- 2020. The Lives, Lore, and Literature of Cranes: A Catechism for Crane Lovers. Lincoln: University of Nebraska-Lincoln Digital Commons and Zea Books. 144 pp. https://digitalcommons.unl.edu/zeabook/93/

Price, A. L. 2001. Cranes: The Noblest Fliers. Albuquerque, NM: Alameda Press. Walkinshaw, L. H. 1949. The Sandhill Crane. Bloomfield Hills, MI: Cranbrook Institute of Science Bulletin 29. 202 pp.

- 1973. Cranes of the World. New York: Winchester Press. 370 pp. von Treuenfels, C.-A. 2007. The Magic of Cranes. New York: H. Abrams. 240 pp. Voss, K. S. 1976. Behavior of the greater sandhill crane. MS thesis. University of Wisconsin, Madison. 
